\title{
LA AUTORIZACIÓN DE PARQUES EÓLICOS MARINOS EN ESPAÑA
}

\author{
BlAnCA SORo MATEO \\ Profesora Titular de Derecho Administrativo \\ Universidad de Murcia \\ blancasm@um.es
}

Recibido: 21 de noviembre de 2011 / Aceptado: 2 de diciembre de 2011

RESUMEN: El trabajo aborda el estudio del régimen jurídico español de los parques eólicos en el mar, regulado especialmente por el Real Decreto 1028/2007, lo que implica un análisis pormenorizado del procedimiento que ha de seguir un promotor de este tipo de instalaciones, desde la solicitud inicial hasta la autorización de la instalación, pasando por la reserva de zona. Se plantean los problemas advertidos y se ofrecen propuestas de reforma inspiradas en la integración de políticas y en la simplificación de procedimientos.

RESUM: El treball aborda l'estudi del règim jurídic espanyol dels parcs eòlics en el mar, regulat especialment pel Reial Decret 1028/2007, la qual cosa implica una anàlisi detallada del procediment que ha de seguir un promotor d'aquest tipus d'instal·lacions, des de la sol·licitud inicial fins a l'autorització de la instal·lació, passant per la reserva de zona. Es plantegen els problemes detectats i s'ofereixen propostes de reforma inspirades en la integració de polítiques i en la simplificació de procediments.

\footnotetext{
ABSTRACT: This study focuses on the legal status of the offshore wind farms in Spain, which implies a detailed analysis of the procedure that has to follow an eventual promoter - from the initial request until the authorization of the installation-. The final goal is to pose the problems and propose solutions in this domain, based in an integrated policy and the simplification of administrative procedure.
} 
PALABRAS CLAVE: Energías renovables — parques eólicos marinos - parques eólicos offshore —régimen jurídico de la energía eólica

PARAULES CLAU: Energies renovables - parcs eòlics marins - parcs eòlics offshore — règim jurídic de l'energia eòlica

KEYWORDS: Renewable energy — wind farms — offshore wind farms — legal status of wind energy

Sumario: I. Instalaciones eólicas en el mar: dificultades y oportunidades en un contexto de crisis. II. La tramitación de las solicitudes de autorización de instalaciones eólicas en el mar territorial. 1. Consideraciones generales. 2. Presupuesto: la necesidad de la previa obtención del otorgamiento de reserva de zona. 2.1. Solicitud de reserva de zona. 2.2. La caracterización del área eólica marina. A. Procedimiento de caracterización del área eólica marina. B. Contenido de la caracterización del área eólica marina. C. Naturaleza de la caracterización del área eólica marina. 2.3. Procedimiento de concurrencia. 2.4. Resolución del procedimiento de reserva de zona. Su impugnación 3. Derechos y deberes del beneficiario. 4. Régimen jurídico de los avales previstos en el Real Decreto 1028/2007. 5. Fase final: el procedimiento de autorización de la instalación. III. Cuestiones que plantea el régimen jurídico vigente. 1. La problemática derivada del desfase del Estudio Estratégico Ambiental del litoral español y del carácter parcial del Real Decreto 1028/2007. Hacia una verdadera planificación integrada del mar. 2. Nuestra propuesta

\section{INSTALACIONES EÓLICAS EN EL MAR: DIFICULTADES Y OPORTUNIDADES EN UN CONTEXTO DE CRISIS}

En el obligado proceso de sustitución energética que vivimos, en un país que cuenta con aproximadamente $8.000 \mathrm{~km}$ de costa, el desarrollo de la energía eólica marina supone un importante reto de futuro. Como consecuencia de lo anterior, y a pesar de la ralentización derivada de la crisis mundial que en España ha supuesto la reducción en un $75 \%$ la potencia eólica marina prevista inicialmente, el estudio de los aspectos jurídicos implicados en la implantación de las instalaciones eólicas en el mar resulta una cuestión de notable importancia. Como es sabido, el desarrollo de la energía eólica en nuestro país ha experimentado un crecimiento muy rápido junto a Alemania y Dinamarca. En el Libro Blanco Energía para el futuro: fuentes de energía renovables 
se sostiene que en la actualidad tenemos la mayor capacidad eólica de generación eléctrica del mundo ${ }^{1}$, ascendiendo $165.000 \mathrm{Mw}^{2}$ nuestro potencial eólico marino.

Para el cumplimiento de los objetivos marcados por el Libro Blanco para una estrategia común y un plan de acción para las energías renovables de 2001, que se concreta en la aportación, por parte de las energías renovables, de un $12 \%$ de la energía primaria demandada en el global de la UE en el año 2010, el Estado español aprobó el Plan de energías renovables en España 2005-2010, de 8 de agosto de 2005. Dicho Plan otorgó un importante papel al desarrollo de la energía eólica, refiriéndose expresamente a la creciente demanda de aerogeneradores marinos, así como a la existencia de una quincena de parques eólicos marinos en distintos países de la UE (Dinamarca, Reino Unido, Irlanda, Suecia, Holanda y Alemania).

En el momento actual, el vigente Plan de energías renovables 2011-2020, aprobado por Acuerdo de Consejo de Ministros de 11 de noviembre de 2011, establece que las fuentes renovables deben representar al menos el $20 \%$ del consumo de energía final en el año 2020 frente al 10,5\% en 2008 - mismo objetivo que para la media de la UE-, junto a una contribución mínima del 10\% de fuentes de energía renovables en el transporte para ese año. Objetivos que, a su vez, han quedado recogidos en la Ley $2 / 2011$, de Economía Sostenible, de conformidad con la Directiva 2009/28/CE del Parlamento Europeo y del Consejo, de 23 de abril de 2009, relativa al fomento del uso de energía procedente de fuentes renovables, y atendiendo a los mandatos del Real Decreto 661/2007, por el que se regula la actividad de producción de energía eléctrica en régimen especial. Ello da buena cuenta de la importancia que desde diversas instancias se otorga al desarrollo de las energías renovables en nuestro país, a pesar de la complicada situación económica actual, y puede afirmarse que la futura implantación de los parques eólicos marinos en España puede situarnos, como en el caso de la energía eólica terrestre, entre los primeros países de nuestro entorno ${ }^{3}$.

\footnotetext{
${ }^{1}$ Libro Blanco Energía para el futuro: fuentes de energía renovables, COM (1996) 576 20.11.1996, pág. 44.

2 Informe renovables 2050: Un informe sobre el potencial de las energías renovables en la España peninsular, Instituto de investigación tecnológica, Comillas, 2005.

${ }^{3}$ Sobre la apuesta de la UE por el fomento del uso de las fuentes de energía renovable vid. BLESA MARTÍNEZ, B., "Nuevas tecnologías que contribuyen a mitigar el cambio climático: las instalaciones sostenibles en el mar territorial”, Revista Aranzadi de Derecho Ambiental, núm. 18, 2020, pp. 341-354.
} 
A nivel financiero, el Reglamento (CE) 663/2009 del Parlamento Europeo y del Consejo, de 13 de julio de 2009, por el que se establece un programa de ayuda a la recuperación económica mediante la concesión de asistencia financiera comunitaria a proyectos del ámbito de la energía ${ }^{4}$ tiene por objeto establecer un programa Energético Europeo para la recuperación (PEER), que permita financiar proyectos en los tres principales ámbitos del sector energético, las infraestructura de gas y electricidad, la energía eólica marítima y la captura y el almacenamiento geológico de carbono, que recibirán respectivamente 2365, 565 y 1050 millones de euros.

A pesar de que la apuesta por la energía eólica marina favorece el desarrollo económico y el cumplimiento de la obligada reducción de emisiones de $\mathrm{CO} 2$ y supone un paso adelante hacia la independencia energética, hacia la seguridad del abastecimiento y hacia el tan renombrado e imprescindible fomento del empleo, los impactos negativos que el funcionamiento de estos parques genera para la protección de los ecosistemas, el paisaje y el patrimonio cultural, para el turismo costero y las actividades recreativas, así como para la pesca, la seguridad del tráfico marítimo y demás actividades económicas, están influyendo en la ralentización de su desarrollo. No se ha de desdeñar, asimismo, el coste derivado de la envergadura de los proyectos y de la complejidad de su construcción y, por supuesto, los costes derivados de la $\mathrm{I}+\mathrm{D}+\mathrm{I}$, sobre todo en relación con las experiencias flotantes, aptas para lechos marinos como el español, que a pocos metros de la costa alcanza profundidades importantes ${ }^{5}$.

Como consecuencia de la ubicación de estas instalaciones, el tratamiento jurídico de las mismas resulta sumamente complejo, en primer término, por las dificultades derivadas de la conjunción de títulos competenciales que confluyen sobre el mar, lo que obliga a tener en cuenta multitud de normas sobre sectores diversos como navegación marítima, pesca, transporte y protección ambiental del medio marino, entre otras. En materia de energía, debemos partir de la competencia exclusiva del Estado para el establecimiento de las bases del régimen energético que se derivan del art. 149.1.25 $\mathrm{CE}$. Otro título competencial que ha de ser tenido en cuenta es la competencia exclusiva del Estado en materia de planificación económica, derivada del art. 149.1.13 ${ }^{\mathrm{a}} \mathrm{CE}$. En desarrollo de

\footnotetext{
${ }^{4}$ Reglamento (UE) no 1233/2010 del Parlamento Europeo y del Consejo, de 15 de diciembre de 2010, por el que se modifica el Reglamento (CE) $n^{\circ} 663 / 2009$, por el que se establece un programa de ayuda a la recuperación económica mediante la concesión de asistencia financiera comunitaria a proyectos del ámbito de la energía.

${ }^{5}$ Sobre el estado actual de la energía eólica marina y sobre las consecuencias económicas y sociales de su implantación, cfr. BLESA MARTÍNEZ, "Nuevas tecnologías..." cit., pp. 347-351.
} 
ambos títulos el legislador estatal dictó la Ley 54/1997, de 27 de noviembre, de Ordenación del Sector Eléctrico y la Ley 21/1992, de 16 de julio, de Industria, que resulta de aplicación supletoria en todo lo no regulado por las normas específicas reguladoras de la actividad de generación, distribución y suministro de la energía y productos energéticos ${ }^{6}$. Por otra parte, también confluye la competencia exclusiva del Estado sobre la legislación civil (art. 149.1.8 ), sobre las bases del régimen jurídico de las AAPP y sobre los contratos y concesiones administrativas (art. 149.1.18 ${ }^{\mathrm{a}}$ ). La Ley 33/2003, de 3 de noviembre, de Patrimonio de las Administraciones Públicas (LPAP) supone el ejercicio por el legislador estatal de su competencia para la regulación del régimen jurídico básico de los bienes públicos, como es el caso del mar territorial, de los recursos naturales de la zona económica y la plataforma continental, de conformidad con el art. 132.2 de la CE. Por último, en este ámbito confluyen títulos conexos con los

\footnotetext{
${ }^{6}$ En primer lugar, el Real Decreto 1955/2000, de 1 de diciembre, por el que se regulan las actividades de transporte, distribución, comercialización, suministros y procedimientos de autorización de instalaciones de energía eléctrica. La disp. Final. Primera del mismo afirma su carácter básico, de conformidad con los arts. 149.1.13 y $149.1 .25^{\mathrm{a}} \mathrm{CE}$, aunque precisa que no tendrá carácter básico para los procedimientos administrativos de autorización de instalaciones de producción transporte y distribución de energía eléctrica en los que sean competentes las CCAA, de conformidad, según nuestra opinión, con el art. 149.1.22 CE, esto es, cuando no afecten a dos CCAA, en cuyo caso la únicas bases que han de respetar éstas al regular estos procedimientos autorizatorios serán las derivadas de la Ley 30/1992, de 26 de noviembre, de Régimen Jurídico de las Administraciones Públicas y del Procedimiento Administrativo Común.
}

En segundo lugar, y por lo que se refiere al Real Decreto 661/2007, de 25 de mayo, por el que se regula la actividad de producción de energía eléctrica en régimen especial, según su disp. final 3, resulta de carácter básico, al amparo de lo establecido en los arts. 149.1.22 y $25 \mathrm{CE}$, salvo en lo relativo a los procedimientos de inclusión en el régimen especial que resulten de competencia autonómica, de acuerdo con el art. 4 del mismo Real Decreto, como tendremos ocasión de analizar infra. Las Comunidades Autónomas pueden desarrollar esta normativa, para los supuestos en que corresponda autorizar a los órganos de la Administración autonómica, teniendo en cuenta que, en virtud del art. 5 del real Decreto 661/2007 sólo podrán regular procedimientos simplificados en el caso de que la potencia de las instalaciones sea no superior a $100 \mathrm{KW}$. Según el art. 5, párrafo 3 del Real Decreto 661/2007, las Comunidades Autónomas, en el ámbito de sus competencias, podrán desarrollar procedimientos simplificados para la autorización de instalaciones cuando éstas tengan una potencia instalada no superior a $100 \mathrm{KW}$. Por último, el Real Decreto 1028/2007, de 20 de julio, por el que se establece el procedimiento administrativo para la tramitación de las solicitudes de autorización de instalaciones de generación eléctrica en el mar territorial, según la disp. final del mismo, se dicta al amparo del art. 149.1.22 ${ }^{\mathrm{a}} \mathrm{CE}$. Realmente debería haber invocado alguna competencia normativa, como los dos Reales Decretos anteriormente citados, ya que esta competencia a la que alude fundamenta la exclusividad de la competencia estatal de gestión. En puridad, la competencia normativa estatal en estos casos se fundamenta en los títulos exclusivos del Estado contenidos en los arts. 149.1.8 (legislación civil) y 149.1.18 $\mathrm{CE}$ (bases del régimen jurídico de las AAPP y sobre los contratos y concesiones administrativas) en la medida en que el las instalaciones objeto de regulación son aquellas que se ubican en el mar territorial, como señalábamos supra En consecuencia, la regulación del régimen jurídico de los parques eólicos marinos corresponde en todo caso y en exclusiva al Estado y así lo reitera el art. 4.2.b del Real Decreto 661/2007.

Un análisis completo de la distribución de competencias entre el estado y las CCAA en materia de energías renovables, puede encontrarse en GONZÁLEZ RÍOS, I, Régimen jurídico administrativo de las energías renovables y de la eficiencia energética, Thomson Reuters-Aranzadi, 2011, pp. 41-54. 
expuestos como protección del medio ambiente (art. 149.1.23 $\mathrm{CE}$ ), especialmente marino, pesca (art. 149.1.19 $\mathrm{CE}$ ), y marina mercante y puertos de interés general (149.1.20 $\mathrm{CE})$.

El segundo motivo fundamental que queremos traer a colación por añadir complejidad al tratamiento jurídico de estas instalaciones tiene que ver con la propia naturaleza jurídica del mar, en parte bien de dominio público, de cuya consideración se deriva un régimen jurídico exorbitante que ha de ser buscado, además de en la normativa específica reguladora de estas instalaciones, en la normativa general sobre bienes públicos y sobre dominio público marítimo-terrestre, sin olvidar la disciplina de los mares contenida en el Derecho Internacional, y especialmente en la Convención de Naciones Unidas sobre Derecho del Mar de 1982 (CONVEMAR).

Por último, otro de los motivos que complican el régimen jurídico de este sector energético deriva de que en la autorización y control de las instalaciones eólicas en el mar van a intervenir órganos procedentes de distintos departamentos, e incluso de distintas Administraciones Públicas ${ }^{7}$. En efecto, la complejidad del tratamiento jurídico dispensado a estas instalaciones también deriva de la compleja tarea de integración de los diversos procedimientos diseñados para la obtención de los diversos títulos habitantes necesarios para la puesta en marcha y funcionamiento de los parques eólicos marinos, regulados a día de hoy, como es sabido, especialmente, por el Real Decreto $1028 / 2007$, de 20 de julio, por el que se establece el procedimiento administrativo para la tramitación de las solicitudes de autorización de instalaciones de generación eléctrica en el mar. Pues bien, si bien son muchos las cuestiones jurídicas a abordar en relación con la energía eólica marina, dedicamos el presente estudio al análisis de la normativa que disciplina el procedimiento administrativo para la instalación de estos parques marinos, adelantando que la regulación de la instalación y puesta en marcha y

\footnotetext{
${ }^{7} \mathrm{El}$ art. 149.1.22 $\mathrm{CE}$ atribuye al Estado, como competencia exclusiva, la autorización de las instalaciones eléctricas cuando su aprovechamiento afecte a otra Comunidad o el transporte de energía salga de su ámbito territorial. En consecuencia, la competencia para la autorización de instalaciones de energía eólica corresponde al Estado o a las CCAA según el lugar en el que se ubican y según afecten a una o varias CCAA. En Real Decreto 661/2007 se establece que la autorización de parques eólicos terrestres corresponderá al Estado cuando afecte a varias CCAA o las CCAA no hayan asumido la competencia en materia energética (art. 4.2.a). Además, independientemente de lo anterior, será competente el Estado en todo caso cuando la potencia supere los $50 \mathrm{MW}$ (art. 4.2.b). El procedimiento aplicable, en este caso, será el regulado por el Real Decreto 1955/2000, como establece el art. 111.1 del mismo y como se deriva de su disp. final Primera. Además, el Real Decreto 661/2007 afirma la competencia estatal, en todo caso, para autorizar estas instalaciones cuando se pretendan ubicar en el mar (art. 4.2.b), en consonancia con lo estipulado por su norma reguladora, esto es, por el Real Decreto 1028/2007 (art. 3).
} 
funcionamiento de estas instalaciones plantea importantes dificultades que requerirán, como se verá, una serie de reformas normativas.

Como consecuencia de todo lo anterior, aunque la apuesta por la energía eólica marina supone vencer los obstáculos derivados de la escasez de suelo, así como la problemática derivada del ajuste a la planificación urbanística y en general a la planificación territorial, cualquier instalación en el mar deberá enfrentarse, en cambio, a todos los condicionamientos que se derivan de las limitaciones de uso de los bienes de dominio público, de otros usos del mar preexistentes, como la pesca, el transporte, la acuicultura, los dragados, las estaciones petróleo y gas, la actividad militar, las actividades de ocio, entre otras, así como los requerimientos ambientales que se derivan, sobre todo, de la normativa sobre EIA y sobre protección de especies y espacios, ruido y ondas electromagnéticas ${ }^{8}$.

\section{LA TRAMITACIÓN DE LAS SOLICITUDES DE AUTORIZACIÓN DE INSTALACIONES EÓLICAS EN EL MAR TERRITORIAL}

1. Real Decreto 1028/2007, de 20 de julio, por el que se establece el procedimiento administrativo para la tramitación de las solicitudes de autorización de instalaciones de generación eléctrica en el mar territorial

El régimen jurídico de las instalaciones de energía eólica marina, hasta el dictado del Real Decreto 1028/2007, de 20 de julio, por el que se establece el procedimiento administrativo para la tramitación de las solicitudes de autorización de instalaciones de generación eléctrica en el mar territorial, había de ser buscado en la normativa general sobre instalaciones de generación de energía eléctrica, y concretamente en la Ley 54/1997, de 27 de noviembre, del Sector Eléctrico. Esta Ley, como es sabido, regula las actividades destinadas al suministro de la energía eléctrica -consistentes en su generación, transporte, distribución, comercialización e intercambios intracomunitarios e internacionales- así como la gestión económica del sistema eléctrico, estableciendo

\footnotetext{
${ }^{8}$ El Gobierno español ha aprobado el Estudio Estratégico Ambiental del Litoral Español (2009) en el que se incluye el mapa de zonas aptas, zonas de exclusión y zonas aptas con condicionantes ambientales, para la instalación de parques eólicos marinos. El objetivo de este estudio estratégico es determinar las zonas del dominio público marítimo-terrestre que, a los solos efectos ambientales, reúnen condiciones favorables para la ubicación de instalaciones eólicas marinas.
} 
dos sistemas: el régimen ordinario $(\text { art. 21) })^{9}$ y el régimen especial (art. 28), considerándose en régimen especial las instalaciones de producción de electricidad que no sobrepasen los $50 \mathrm{MW}$ de potencia instalada, en cuatro concretos supuestos. En primer término, cuando dichas instalaciones utilicen la cogeneración u otras formas de generación de electricidad asociadas a actividades no eléctricas, siempre que supongan un alto rendimiento. En segundo lugar, cuando utilicen como energía primaria cualquiera de las energías renovables no consumibles, biomasa u otro tipo de biocarburante y siempre y cuando su titular no realice actividades en régimen ordinario. Asimismo, y en tercer lugar, cuando se utilicen, como energía primaria, residuos no renovables. Y, por último, las instalaciones de tratamiento y reducción de residuos agrícolas, ganaderos y de servicios, con una potencia instalada de hasta $25 \mathrm{MW}$, siempre que supongan un alto rendimiento energético. Así, las instalaciones de energía eólica ubicadas en el mar, que utilicen como energía primaria la eólica, de conformidad con lo anterior, quedaban incardinadas en el segundo supuesto enunciado, por lo que el régimen jurídico aplicable, hasta el dictado de la norma específica reguladora de las mismas, como señalábamos, ha sido el sistema de régimen especial regulado por la Ley 54/1997, de 27 de noviembre, del Sector Eléctrico.

Siguiendo la tendencia simplificadora auspiciada por el conocido control integrado de la contaminación en el ámbito del Derecho Ambiental, el Real Decreto 1028/2007 pretendió aglutinar en un único procedimiento administrativo la mayoría de autorizaciones necesarias para poner en marcha las instalaciones de energía eólica marina, autorizaciones que encuentran su razón de ser en la intervención administrativa del sector energético, en la protección de los espacios físicos donde se vayan a instalar y en la salvaguarda de las diversas competencias sectoriales implicadas de las distintas Administraciones Públicas.

El Real Decreto 1028/2007 define parque eólico o instalación de generación eólica marina como "todo proyecto de inversión que se materialice en la instalación integrada de uno o varios aerogeneradores, interconectados eléctricamente mediante redes propias, compartiendo una misma estructura de accesos y control, con medición de

\footnotetext{
9 El titular de la instalación de producción de energía eléctrica, para obtener la autorización administrativa, deberá previamente obtener la autorización del punto de conexión a las redes de transporte o de distribución. Posteriormente, deberá inscribirse en el registro donde estén inscritas las instalaciones de producción de electricidad que hayan sido autorizadas (incluyendo las condiciones de instalación y la potencia generada).
} 
energía propia y con conexión a la red de transporte, y ubicado físicamente en el mar territorial”.

De esta definición puede deducirse que, en principio, el procedimiento regulado en la norma de referencia se aplicará sólo y exclusivamente a las instalaciones que pretendan ubicarse en el Mar Territorial (MT). No obstante, en virtud de la disposición adicional quinta de la norma, dicho procedimiento podrá ser de aplicación también a las instalaciones de generación eólica que se pretendan ubicar en la zona contigua o en la zona económica exclusiva del Dominio Público Marítimo-Terrestre ${ }^{10}$. Por otra parte, también se refiere el Real Decreto en su art. 32 a las instalaciones de generación de energía eléctrica ubicadas en el MT que utilicen tecnología distinta de la eólica piénsese en la oleomotriz-, señalando que para la obtención de autorizaciones y concesiones administrativas precisas para la construcción y ampliación de las instalaciones de generación de electricidad de origen renovable que se encuentren ubicadas físicamente en el mar territorial y de tecnología diferente a la eólica se establece un procedimiento simplificado que comienza con la solicitud de autorización administrativa regulada en el art. 24 del Real Decreto 1028/2007, resultando con carácter subsidiario de aplicación del Real Decreto 1955/2000, de 1 de diciembre, no estableciéndose, en este caso y a diferencia como veremos a continuación de lo que sucede e relación con las instalaciones eólicas marinas, ninguna limitación mínima de potencia.

En efecto, las instalaciones de generación eólica marina que pretendan ubicarse en el Mar Territorial tendrán una potencia instalada mínima superior a $50 \mathrm{MW}$ y, en todo caso, se regirán por lo establecido en la Ley 22/1988, de 28 de julio, de Costas y en el Reglamento General para su desarrollo y ejecución aprobado por Real Decreto 1471/1989, de 1 de diciembre (art. 2 del Real Decreto 1028/2007). De lo anterior cabe deducir, por no existir disposición en sentido contrario, que a la instalación de parques eólicos marinos en otras zonas, aunque no se diga expresamente como sucede en relación con las instalaciones de energía eléctrica que se ubiquen en el mar y utilicen tecnología distinta de la eólica, no se aplica dicho límite mínimo. Asimismo, es preciso advertir que dicho límite podrá ser modificado a alza o a la baja hasta un $20 \%$ para

\footnotetext{
${ }^{10}$ En este caso, continúa señalando la disposición, la resolución del procedimiento de concurrencia y otorgamiento de la reserva de zona a que hace referencia el art. 17 del Real Decreto, será dictada por el Ministro de Industria, Turismo y Comercio.
} 
proyectos particulares según la disposición final 2 del Real Decreto 1028/2007 ${ }^{11}$. En este sentido puede entenderse el contenido del art. 25.1.c, que establece la posibilidad de que se solicite la autorización de instalación de parques eólicos marinos de potencia inferior o igual a $50 \mathrm{MW}$, que serán incluidas en el régimen especial del Real Decreto

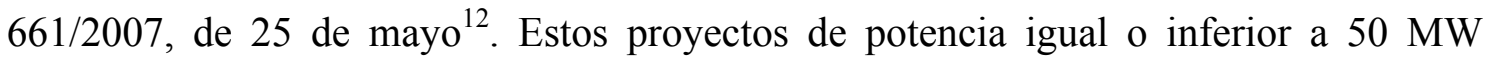
podrían consistir en proyectos de investigación y desarrollo tecnológico, aunque el precepto establece absoluta discrecionalidad al Ministerio de Industria, Turismo y Comercio para determinar estas excepciones a la regla general del art. 2 del Real Decreto $1028 / 2007$.

\section{La necesidad de la previa obtención del otorgamiento de reserva de zona}

\subsection{Solicitud de reserva de zona}

De modo previo a la obtención de la autorización de las instalaciones de energía eólica marina es necesario que el promotor obtenga la denominada reserva de zona. Para ello presentará la solicitud de reserva de zona para la realización de los estudios previos a la solicitud de autorización de la instalación, que será dirigida a la DGPEM, junto con el estudio de impacto ambiental de este proyecto de investigación ante el órgano competente o bien, como sabemos, en cualquiera de los lugares a que se refiere el art. 38 de la LRJPAC (art. 7 Real Decreto 1028/2007) ${ }^{13}$.

Es necesario advertir, a este respecto, que a partir del inicio del procedimiento de otorgamiento de reserva de zona tendrán lugar dos evaluaciones de impacto ambiental,

\footnotetext{
11 Entendemos que la referencia que efectúa el Real Decreto a proyectos particulares quiere aludir a proyectos concretos.

12 El Real Decreto 661/2007, de 25 de mayo, por el que se regula la actividad de producción de energía eléctrica en régimen especial. Esta norma atribuye a la Administración General del Estado, a través de la DGPEM del Ministerio de Industria, Turismo y Comercio, la tramitación de las solicitudes de autorización de instalaciones de generación eólica en el mar territorial (art. 25.1.c Real Decreto 1028/2007). De igual modo, es importante hacer mención de la Ley 54/1997, de 27 de noviembre, del Sector Eléctrico, en la que, en su art. 21, se establece que la construcción, explotación, modificación sustancial y cierre de cada instalación de producción de energía eléctrica estará sometida al régimen de autorización administrativa previa en los términos establecidos en esta misma Ley, siendo de carácter reglado su otorgamiento.

${ }^{13}$ En virtud del art. 7 del Real Decreto 1028/2007, deberá presentarse ante el órgano correspondiente de la delegación o subdelegación del gobierno que dependa funcionalmente del Ministerio de Industria, Turismo y Comercio. Este trámite es definido por ALENZA GARCÍA como acto de preconcesión de la autorización de la autorización del parque eólico marino (vid. ALENZA GARCÍA, J.F., "La autorización de parques eólicos marinos" en Sanz Larruga, F.J., García Pérez, M., Estudios sobre la ordenación, planificación y gestión del litoral: hacia un modelo integrado y sostenible, Fundación Pedro Barrié de la Maza e Instituto de Estudios Económicos de Galicia-Observatorio del litoral, A Coruña, 2009, p. 505).
} 
una inserta en el procedimiento de reserva de zona, y otra inserta en el procedimiento de autorización de la instalación. Por lo que hace a la primera de ellas, el Real Decreto se refiere a la misma expresamente en su art. 23, que somete a Evaluación de impacto ambiental la realización de actividades de investigación que vayan a realizar los titulares de la reserva de zona en la poligonal correspondiente ${ }^{14}$. En este caso, la memoria que forma parte del Anteproyecto de la instalación de energía eólica marina, que acompañará a la solicitud de reserva de zona, y, como veremos infra, a los demás proyectos presentados en el procedimiento de concurrencia (arts. 8 y 14) deberá contener la información necesaria para la iniciación de la evaluación de impacto ambiental del proyecto de investigación. La competencia para realizar la declaración de impacto ambiental, en este caso, corresponderá al Ministerio de Medio Ambiente y Medio Rural y Marino, en la medida en que la competencia para resolver el procedimiento de otorgamiento de reserva de zona corresponde a la Secretaría de Estado de Energía, dependiente del Ministerio de Industria, Turismo y Comercio, que en este caso sería el órgano sustantivo.

Por otra parte, además de estas evaluaciones de impacto ambiental, de acuerdo con la disposición adicional tercera del Real Decreto 1028/2007, el actual Ministerio de Industria, Turismo y Comercio y el Ministerio de Medio Ambiente y Medio Rural y Marino, en el ámbito de sus competencias respectivas y previa consulta a las Administraciones públicas afectadas, realizarán conjuntamente un Estudio Estratégico Ambiental del Litoral Español (EEALE). Se trata de un plan ambiental aprobado por Resolución de 30 de abril de 2009, de la Secretaría General de la Energía y de la Secretaría General del Mar, cuyo objetivo consiste en la determinación de las zonas del dominio público marítimo-terrestre que, a los solos efectos ambientales, reúnen condiciones favorables para la instalación de parques eólicos marinos ${ }^{15}$. Con esta finalidad, el EEALE establece una clasificación en zonas aptas, aptas con

\footnotetext{
${ }^{14}$ Cfr. art. 19.1 del Real Decreto 1028/2007.

${ }^{15}$ SANZ LARRUGA advierte al respecto que como ya existe "Estudio estratégico del litoral español", la reserva de zona deberá efectuarse sobre una de las zonas aptas o zonas aptas con condicionantes ambientales, en las 74 áreas eólicas marinas en que se divide el litoral español. Cfr. SANZ LARRUGA, J., "Los parques eólicos marinos en el marco de la gestión integrada del litoral" en Torres López, M.A., Arana García, E. (dirs.), Energía eólica: cuestiones jurídicas, económicas y ambientales, Civitas, Madrid, 2010, p. 339.
} 
condicionantes ambientales o de exclusión del mar territorial para la instalación de instalaciones eólicas marinas ${ }^{16}$.

Dicho lo anterior, y continuando con el análisis de la tramitación del procedimiento de reserva de zona, la solicitud de reserva de zona, además de ir acompañada del estudio de impacto ambiental del proyecto de investigación del área eólica marina de que se trate, deberá contener, amén de cumplir el art. 70 de la LRJPAC, la documentación a que se refiere el art. 8 del Real Decreto 1028/2007, esto es, una acreditación de la capacidad del solicitante ${ }^{17}$, una memoria resumen del proyecto, un anteproyecto de la instalación por triplicado y una separata para las Administraciones Públicas, organismos y empresas de servicio público o de servicios de interés general que puedan verse afectados por el proyecto (art. 8 Real Decreto 1028/2007).

La memoria-resumen detallará la superficie para la que se solicita el proyecto, los estudios previos que se vayan a realizar y el tiempo estimado de realización ${ }^{18}$.

${ }^{16}$ Dicho Estudio ha sido sometido al procedimiento previsto en la Ley 9/2006, de 28 de junio, sobre Evaluación de los efectos de determinados planes y programas sobre el medio ambiente, tal y como establece, asimismo la aludida disp. adic. tercera. Esta evaluación ambiental estratégica, junto con las posteriores evaluaciones de impacto ambiental y la caracterización de las Áreas Eólicas Marinas previstas en el Real Decreto 1028/2007, permitirán una mayor eficiencia en los procedimientos de autorización, facilitando a los promotores la elección de las zonas más adecuadas, desde el punto de vista ambiental, para la ubicación y el diseño de sus proyectos. La Resolución de 30 de abril de 2009, de la Subsecretaría, dispone la publicación de la Resolución conjunta de la Secretaría General de Energía y de la Secretaría General del Mar, por la que se aprueba el Estudio Estratégico Ambiental del litoral español para la instalación de parques eólicos marinos. El contenido de este Estudio puede consultarse en los siguientes enlaces

web: http://www.mma.es/portal/secciones/evaluacion_ambiental/planes_programas/planes_ea/pdf/Estudio_Estr ategico Ambiental 11 12 07.pdf http://www.mma.es/portal/secciones/evaluacion ambiental/planes programas/planes ea/peoP009.htm

${ }^{17}$ En relación al art. 121 del Real Decreto 1955/2000, el solicitante deberá acreditar su capacidad legal, técnica y económico-financiera para la realización del proyecto. En efecto, dispone el precepto que los solicitantes deberán acreditar su capacidad legal, técnica y económico-financiera para la realización del proyecto. Asimismo, los solicitantes de autorizaciones de transporte deberán cumplir los requisitos establecidos para el desarrollo de esta actividad, establecidos en el artículo 37 del Real Decreto. Por su parte, los solicitantes de autorizaciones de producción deberán cumplir los siguientes requisitos: capacidad legal (forma de sociedades mercantiles de nacionalidad española o en su caso de otro Estado miembro de la Unión Europea con establecimiento permanente en España, teniendo como objeto social exclusivo el desarrollo de dicha actividad, conforme al artículo 2 del Real Decreto), capacidad técnica (haber ejercido la actividad de producción o transporte, según corresponda, de energía eléctrica durante, al menos, los últimos tres años, contar entre sus accionistas con, al menos, un socio que participe en el capital social con un porcentaje igual o superior al $25 \%$ y que pueda acreditar su experiencia durante los últimos tres años en la actividad de producción, transporte, según corresponda o tener suscrito un contrato de asistencia técnica por un período de tres años con una empresa que acredite experiencia en la actividad de producción, transporte, según corresponda) y, por último, capacidad económica, la cual se entenderá cumplida cuando la empresa solicitante aporte acreditación que garantice la viabilidad económica financiera del proyecto, pudiendo la Administración competente eximirla de esta acreditación para aquellas que vinieran ejerciendo esta actividad con anterioridad.

${ }^{18}$ Siempre con un máximo de dos años, coincidentes con el plazo máximo de vigencia del derecho de reserva de zona. 
Asimismo será necesario, además, aportar una serie de documentos que hagan referencia a los siguientes extremos: la superficie delimitada por las coordenadas geográficas de los vértices de la línea poligonal que la comprende, el objeto de investigación, la instalación a implantar, el plan de inversiones y el plan de restauración adecuado para restituir el dominio público a su estado original para el caso de que el proyecto no llegue a ejecutarse.

En cuanto al anteproyecto de la instalación, deberá contener una memoria, los planos de la instalación a escala mínima 1:50.000, incluyendo las líneas de evacuación previstas y un presupuesto estimado del proyecto de instalación. En esta memoria deberán ir reflejadas las siguientes especificaciones: ubicación de la instalación, origen, recorrido y fin de las líneas de evacuación eléctrica de la misma, objeto de la instalación indicando el número de aerogeneradores previstos, su potencia y ubicación, características principales de la instalación, condiciones de eficiencia energética, técnicas y de seguridad de la instalación, información necesaria para la iniciación de la Evaluación de Impacto Ambiental, circunstancias del emplazamiento de la instalación y criterios elegidos para su emplazamiento físico, razones de cualquier índole que justifiquen la implantación del parque en la zona, descripción de los recursos eólicos, basados en datos históricos y modelos fiables y evaluación cuantificada de la energía eléctrica que va a ser transferida a la red, estudio de viabilidad, condiciones de tráfico marítimo de la zona y protección de la navegación y de la vida humana en el mar.

Una vez presentada la solicitud, si la DGPEM detectara que no reúne, bien los requisitos del art. 70 de la LRJPAC o bien los exigidos por el art. 8 del Real Decreto 1028/2007, requerirá al interesado para que, en un plazo de diez días, subsane la falta o acompañe los documentos preceptivos, con indicación de que, si así no lo hiciera, se le tendrá por desistido de su petición, previa resolución que deberá ser dictada en los términos previstos en el artículo 42 de la LRJPAC. Este plazo podrá ser ampliado prudencialmente, hasta cinco días, a petición del interesado o iniciativa del órgano, cuando la aportación de los documentos requeridos presente dificultades especiales (art. 71 de la LRJPAC) ${ }^{19}$.

\footnotetext{
19 Se ha de tener en cuenta, además, que el órgano competente podrá recabar del solicitante la modificación o mejora voluntarias de los términos de aquélla. De ello se levantará acta sucinta, que se incorporará al procedimiento (art. 71.3 del real Decreto 1028/2007).
} 


\subsection{La caracterización del área eólica marina}

A. Procedimiento de caracterización del área eólica marina

Admitida a trámite la solicitud y con anterioridad al acuerdo de iniciación del procedimiento de concurrencia previo al otorgamiento de la reserva de zona, es necesario que exista una caracterización de área eólica marina vigente sobre el área solicitada. Si no existiera, o se previera que su vigencia no se fuera a extender hasta la resolución del procedimiento de concurrencia ${ }^{20}$, la DGPEM procederá a iniciar el procedimiento de caracterización de la misma (art. 9).

Así, desde la entrada en el registro del órgano competente de la solicitud o, en su caso, desde la subsanación de los defectos de presentación detectados en la solicitud, en su caso, la DGPEM tendrá un plazo de 20 días para efectuar consultas al operador del sistema y gestor de la red de transporte $^{21}$, así como a las Instituciones y Administraciones previsiblemente afectadas por la ejecución del proyecto eólico en el área de estudio. Además, solicitará informe preceptivo a los Ministerios de Fomento, Medio Ambiente y Medio Rural y Marino y Defensa. Las entidades consultadas tendrán un plazo máximo de 90 días naturales para enviar a la DGPEM, en formato electrónico para facilitar su copia y difusión, los comentarios relacionados con la posibilidad de instalar un parque eólico marino en la zona considerada, además de cualquier indicación que resulte beneficiosa en relación con la ubicación y en el ámbito de sus competencias (art. 11 del Real Decreto 1028/2007) ${ }^{22}$.

Como puede observarse, la norma distingue entre consultas e informes, siendo estos últimos solicitados a órganos de la Administración estatal de carácter preceptivo, aunque no vinculantes ${ }^{23}$. Por su parte, la participación de las Comunidades Autónomas y de los Ayuntamientos tendrá lugar, en cambio, a través de consultas. En cuanto al

\footnotetext{
${ }^{20}$ Téngase en cuenta que la caracterización de área eólica marina, en virtud del art. 13 del Real Decreto 1028/2007, tiene una vigencia de 5 años, contados a partir del día siguiente al de la publicación del anuncio de la misma.

${ }^{21}$ El operador del sistema, según el art. 34 de la Ley 54/1997, de 27 de noviembre, del Sector Eléctrico, será el gestor de la red de transporte y su función principal consiste en la de garantizar la continuidad y seguridad del suministro eléctrico y la correcta coordinación del sistema de producción y transporte, ejerciendo sus funciones en coordinación con los operadores y sujetos del Mercado Ibérico de la Energía Eléctrica bajo los principios de transparencia, objetividad e independencia.

${ }^{22}$ El operador del sistema y gestor de la red de transporte deberá, asimismo, enviar un informe, anualmente y con horizonte temporal de cinco años, sobre la capacidad de evacuación máxima de la red de transporte próxima a las áreas de estudio y una estimación de la potencia máxima a instalar en el área.

${ }^{23}$ Cfr. art. 83 de la LRJPAC.
} 
plazo de emisión de los referidos informes no queda claro, sin embargo, si resulta de aplicación el plazo de 90 días que se establece en relación con las "entidades consultadas" y no a los órganos, en el caso de los Ministerios, o el general de diez días derivado del art. 83.2 de la LRJPAC. Podría entenderse que el cumplimiento del plazo de 90 días aplicable a las aludidas entidades permite un plazo para la emisión de los informes en los mismos términos.

Por otra parte, en el caso de que los Ministerios no emitieran el informe correspondiente en el plazo referido, y aunque efectivamente el informe se configura como preceptivo y no vinculante, resulta determinante para la resolución del procedimiento de caracterización y, por lo que considero que podría interrumpirse el plazo de los trámites sucesivos. En sentido contrario, respecto de la respuesta a las consultas formuladas a las entidades, entre las que se encuentran las CCAA y los Ayuntamiento, el Real Decreto establece expresamente que si en el plazo establecido no se recibiera contestación alguna por parte de las entidades, se entenderá que no existen objeciones por su parte (art. 11, párrafo 2).

La caracterización de área eólica marina se hará pública en el BOE y en la página web del Ministerio de Industria, Turismo y Comercio, mediante un anuncio en el que se indicará la existencia de dicho documento de caracterización y los datos referentes a los lugares donde puede consultarse, como la Dirección General de Política Energética y Minas del Ministerio de Industria, Turismo y Comercio y la Delegación de Gobierno de la Comunidad Autónoma lindante con el área caracterizada (art. 13). En el mismo anuncio se convocará la apertura del procedimiento de concurrencia previsto en los arts. 14 y ss. del Real Decreto 1028/2007. La caracterización del área tendrá una vigencia de cinco años desde el día siguiente al de la publicación de su anuncio.

\section{B. Contenido de la caracterización del área eólica marina}

La caracterización de área eólica marina versará sobre la incidencia de una instalación marina en el interior del área considerada, justificando la conveniencia o no de realizar el proyecto, y estableciendo, en su caso, qué ubicaciones son más adecuadas y cuáles presentarían más dificultades (art. 12.1 del Real Decreto 1028/2007).

Por lo que se refiere al alcance de la caracterización de área eólica marina, ésta tendrá, en general, carácter indicativo. Ahora bien, tendrá carácter limitativo por lo que se 
refiere al establecimiento de la potencia máxima a instalar para la totalidad del área y/o para las subdivisiones interiores que en ella se establezcan, vinculando asimismo si determina la imposibilidad de instalación por motivos de defensa nacional, serio riesgo u obstáculo para la navegación y el tráfico marítimo o especial protección del medio ambiente en el interior del área estudiada (art. 12.4 del Real Decreto 1028/2007).

A la hora de formular la caracterización, el órgano competente tendrá en cuenta que no podrán otorgarse ninguna de las autorizaciones reguladas por este Real Decreto en las zonas definidas en el art. 5, debiendo determinar la imposibilidad de instalación en aquellas áreas marinas en las que existan dispositivos de separación del tráfico marítimo, ni en sus zonas aledañas, en los accesos a los puertos de interés general o a zonas en las que existan terminales de carga o descarga refinerías, factorías químicas y petroquímicas o instalaciones para el almacenamiento y distribución de productos químicos o petroquímicos o de combustibles líquidos y en las zonas a evitar por los buques en tránsito a la altura de las Islas Canarias contenidas en la Resolución de la Organización Marítima Internacional 134(53) de 22 de julio de 2005, o en las que puedan sustituir a éstas. A los efectos de su protección, también habrán de ser tenidas en cuenta las reservas marinas contempladas en el art. 13 de la Ley 3/2001, de 26 de marzo, de Pesca Marítima del Estado ${ }^{24}$.

Sorprende, en este sentido, que el Real Decreto 1028/2007 no haga referencia alguna, en este orden de cosas, a las áreas marinas protegidas distintas de las reservas marinas de pesca contempladas en la Ley 3/2001, y que la Ley 41/2010, de 29 de diciembre, de Protección del medio marino haya olvidado modificar en esta lógica dicha norma reglamentaria.

\footnotetext{
${ }^{24}$ El art. 13 de la Ley 3/2001, de Pesca Marítima del Estado establece:

"1. El Ministro de Agricultura, Pesca y Alimentación, mediante Orden ministerial, podrá declarar zonas de protección pesquera para favorecer la protección y regeneración de los recursos marinos vivos. Dichas zonas, de acuerdo con la finalidad específica derivada de sus especiales características, podrán ser calificadas como: a. Reservas marinas. b. Zonas de acondicionamiento marino. c. Zonas de repoblación marina.

2. La declaración de estas zonas se realizará previo informe del Instituto Español de Oceanografía, del Ministerio de Medio Ambiente, del Ministerio de Defensa, en el caso de que incida sobre zonas declaradas de interés para la Defensa Nacional o zonas de seguridad de instalaciones militares, del Ministerio de Fomento, en el caso de que afecte al servicio portuario, así como de las Comunidades Autónomas afectadas, sobre aspectos de su competencia. La declaración establecerá, en todo caso, la delimitación geográfica de la zona".
} 
Visto el objeto y los condicionantes de la caracterización del área eólica marina, por lo que se refiere al contenido de la misma, contendrá una estimación de la cantidad de energía máxima evacuable a través de las redes eléctricas de transporte y la incidencia que un proyecto eólico marino ocasionaría sobre los elementos que componen su entorno. Así, se determinarán los efectos previsibles sobre la actividad pesquera, la flora y la fauna, las aves, la navegación marítima y aérea, el turismo, el patrimonio histórico y arqueológico y el paisaje, la geomorfología y las comunidades biológicas del fondo marino, las playas, la dinámica litoral y la estabilidad de las costas adyacentes, los espacios marinos sometidos a un régimen de protección ambiental, la explotación de recursos minerales, la incidencia en materia de defensa y seguridad, los cables y tuberías submarinas y cualquier otro aspecto que se considere de interés. Como puede observarse, esta última parte del contenido de la caracterización coincide prácticamente con el contenido de una declaración de impacto ambiental.

C. Naturaleza de la caracterización del área eólica marina

Una cuestión clave a resolver en sede de procedimiento de instalación de los parques eólicos marinos, es la relativa a la naturaleza de la caracterización del área eólica marina que estamos analizando. Recordemos que el promotor de la instalación solicita la reserva de zona para el estudio de un área marina sobre la que la Administración competente debe efectuar una caracterización si no existiera una vigente. Debemos indagar, pues, si dicha caracterización es un acto finalizador de un procedimiento -el de caracterización- o si, por el contrario, se trata de un acto de trámite inserto en el procedimiento de otorgamiento de reserva de zona.

El procedimiento de otorgamiento de reserva de zona es un procedimiento compuesto cuando en él se incardina el de caracterización, que no siempre tendrá lugar, porque puede darse el caso de que exista una caracterización vigente sobre la zona en cuestión, dada su vigencia temporal ${ }^{25}$. Al igual que sucede con la declaración de impacto ambiental, , tampoco en este caso, de la regulación que de la misma lleva a cabo el Real Decreto que analizamos, queda claro si goza de la naturaleza de acto de trámite cualificado o no, a efectos de interposición del recurso directo, de conformidad con el

\footnotetext{
${ }^{25}$ La vigencia de la caracterización se extiende hasta 5 años después de su publicación. No obstante, es posible que antes del transcurso de dicho se proceda a su revisión, que podrá dar lugar a su modificación o a su sustitución cuando se dicte un nuevo acto de caracterización sobre el mismo área.
} 
art. 107 de la LRJPAC. Para resolver esta cuestión es necesario traer a colación el distinto carácter, indicativo y determinante, del diverso contenido de la caracterización. En efecto, todo el contenido determinante a que nos referíamos supra, esto es, el establecimiento de la potencia máxima a instalar y la eventual determinación sobre la imposibilidad de instalación por motivos de defensa nacional, serio riesgo u obstáculo para la navegación y el tráfico marítimo o especial protección del medio ambiente en el interior del área estudiada deciden directa o indirectamente sobre el fondo del asunto y, en su caso, esto es, en relación con las últimas determinaciones, pueden implicar imposibilidad de continuar el procedimiento. Así, atendiendo al contenido de la caracterización, que incluso puede determinar la imposibilidad de conceder la autorización a la instalación, de conformidad con el art. 5 del Real Decreto 1028/2007, podemos considerar que, a todas luces, se trata de un acto de trámite cualificado que forma parte del procedimiento de otorgamiento de reserva de zona. De este modo, pues, no resulta necesario esperar a la resolución del procedimiento de otorgamiento de reserva de zona para poder recurrir estos extremos y, en consecuencia, contra la misma cabe recurso de alzada ante el Secretario de Estado de Energía, en el plazo de un mes contado a partir del día siguiente a su publicación oficial ${ }^{26}$.

\section{La revisión de la caracterización del área eólica marina}

Como señalábamos supra, la caracterización de área eólica marina tendrá una vigencia temporal de cinco años desde el día siguiente al de la publicación del anuncio de la misma.

No obstante, la DGPEM llevará a cabo la revisión de oficio de la caracterización, antes de la finalización del período de vigencia de la misma, cuando así lo considere o cuando se produzca una solicitud para instalación eólica marina en el interior de un área cuya caracterización esté caducada o cuando no se prevea que la vigencia de la caracterización pueda extenderse hasta la resolución del procedimiento de concurrencia. Así, cada vez que se produzca una nueva solicitud, previamente a la apertura de un procedimiento de concurrencia, se revisará la caracterización de área en lo concerniente

\footnotetext{
${ }^{26}$ BUITRAGO MONTORO y GARAY IBARRECHE consideran que se trata de una declaración de voluntad administrativa de contenido múltiple, en parte, verdadero acto administrativo $\mathrm{y}$, en parte, acto de trámite (BUITRAGO MONTORO, A., GARAY IBARRECHE, B., "Energía eólica marina", en Becher y otros (dirs.) Tratado de Energías Renovables II. Aspectos jurídicos, Iberdrola-Aranzadi, 2010, p. 316.
} 
al operador del sistema y gestor de la red de transporte, solicitando un informe al mismo con el contenido y los plazos a cumplir (art. 13 in fine). Esta revisión de oficio, como es obvio, deberá tramitarse de conformidad con la LRJPAC.

\subsection{Procedimiento de concurrencia}

Las características de la plataforma continental de las costas españolas supone que existan zonas más idóneas para la instalación de parques eólicos marinos fijos en grandes concentraciones, por lo que el legislador, según reza la propia Exposición de Motivos de la norma reguladora, ha decidido someter a un procedimiento de concurrencia a los promotores de estas instalaciones. De este modo, obviamente también se garantiza la elección del mejor proyecto. Así, una vez hecho público el documento de caracterización de área eólica marina, si es que no existiera ninguno vigente, la DGPEM abrirá un procedimiento de concurrencia que tendrá como ámbito de aplicación la totalidad del área eólica marina para la cual se realizó la solicitud de reserva de zona. En el caso de que ya existiera una caracterización de área vigente, se publicará igualmente un anuncio de apertura del procedimiento de concurrencia en el $\mathrm{BOE}$, en el que se comunicará la existencia de un documento de caracterización del área vigente, los lugares de consulta del mismo y su período de vigencia. En ambos casos se concederá un plazo de tres meses, contado a partir del día siguiente del anuncio oficial, para que cualquier promotor interesado pueda concurrir con un proyecto de instalación de parque eólico marino en el área solicitada por el promotor inicial. En este plazo, los interesados podrán presentar una solicitud, con la documentación correspondiente ${ }^{27}$, incluyendo el justificante de haber depositado un aval en la Caja General de Depósitos a favor de la DGPEM, por una cuantía del 1 por 100 del presupuesto de la instalación de generación eólica marina prevista. Además, el nuevo promotor que concurra mediante su solicitud, lo hará para una poligonal que se encuentre ubicada en el interior del área o áreas convocadas. Asimismo, el promotor inicial, esto es, el que presentó la solicitud de reserva de zona, deberá depositar dicho aval y presentar el justificante en el mismo

\footnotetext{
${ }^{27}$ En virtud del art. 8 del Real Decreto 1028/2007, la documentación que acompañará a la solicitud de reserva de zona será una acreditación de la capacidad del solicitante, una memoria resumen, un anteproyecto de la instalación de generación eólica marina por triplicado y una separata para las administraciones Públicas.
} 
plazo de tres meses, pudiendo realizar las modificaciones que considere oportunas en la solicitud inicial ${ }^{28}$.

Todos los interesados, incluido el promotor que presentó su solicitud en primer lugar, deberán presentar, en el mismo plazo de tres meses, una solicitud u oferta de prima, cuyo valor se aplicará a lo largo de toda la vida útil de la instalación ${ }^{29}$. Pero, ¿qué significa esta precisión? No queda claro si la prima es o no actualizable, de conformidad con las oscilaciones del IPC. El art. 44 del Real Decreto 661/2007 establece que los importes de las primas se actualizarán anualmente, teniendo como referencia el IPC. Masao Javier LÓPEZ SAKo ha sostenido que se debe entender que la finalidad del Real Decreto 1028/2007 es asegurar, no la congelación de la prima durante toda la vida útil de la instalación, sino el establecimiento del período durante el cual se tiene derecho a su percepción ${ }^{30}$. A nuestro modo de ver, el Real Decreto 1028/2007 sí que está congelando la prima durante todo el período de vigencia de la instalación, aunque ello resulta criticable, en la medida en que la vida útil de la instalación puede prolongarse en el tiempo durante más de veinte años. No obstante, es la regulación que existe, dada la especialidad de esta norma en relación con el Real Decreto 661/2007. Además ha de precisarse que dicha oferta de prima no podrá tener un valor superior al derivado del art. 38.1 del Real Decreto 661/2007.

Para garantizar la elección del mejor proyecto, tras la apertura del procedimiento de concurrencia, se creará un Comité de valoración adscrito al Ministerio de Industria y Turismo y Comercio, encargado de valorar las solicitudes de reserva de zona presentadas y de efectuar una propuesta de resolución que será elevada al Secretario de Estado de Energía para el dictado de la resolución que ponga fin al procedimiento de concurrencia. Este Comité estará presidido por el Director General de Política Energética y Minas, o persona en quien delegue ${ }^{31}$. Se trata de un Comité de

\footnotetext{
${ }^{28}$ Es necesario resaltar que no podrá abrirse un procedimiento de concurrencia para un área para la cual ya exista otro procedimiento de concurrencia sin resolver.

${ }^{29}$ Dicha oferta irá expresada en $€ / \mathrm{kWh}$ producido (con cuatro decimales), y será de valor no superior al establecido en el art. 38.1 del Real Decreto 661/2007, es decir, 8,43 c€/kWh y el límite superior de 16,40 $\mathrm{c} € / \mathrm{kWh}$.

${ }^{30}$ Cfr. LÓPEZ SAKO, M. J., Regulación y autorización de los parques eólicos, Civitas, Madrid, 2008, p. 515.

${ }^{31}$ Este Comité de Valoración estará compuesto, según el Real Decreto 1028/2007 por: el Subdirector General de Planificación Energética del Ministerio de Industria, turismo y Comercio, el Subdirector General de Energía Eléctrica del mismo Ministerio, un representante con rango de Subdirector General designado por la Dirección General de Costas del Ministerio de Medio Ambiente, un representante con rango de Subdirector General designado por la Dirección General de Calidad y Evaluación Ambiental del
} 
composición eminentemente estatal, esto es integrado por once representantes de la Administración General del Estado más el Secretario, con voz pero sin voto y un representante por cada CCAA que linde con el área marina. Además, el presidente del Comité podrá nombrar otros miembros representantes de cualquier otro departamento ministerial y/o de la Administración o Administraciones de las CCAA afectadas, cuando así lo considere.

El Comité de Valoración se reunirá para calificar las solicitudes de autorización presentadas, teniendo en cuenta que cuando sólo exista una solicitud o los proyectos presentados no se solapen, y la potencia o suma de sus potencias no exceda el límite máximo establecido por el operador del sistema o gestor de la red de transporte en la caracterización de área eólica marina, dicho Comité elevará Propuesta favorable de Resolución al Secretario de Estado de la Energía, de tantas reservas de zona como proyectos existan, siempre y cuando las condiciones para la autorización del proyecto o proyectos de las instalaciones eólicas marinas sean las adecuadas.

Si el Comité de Valoración lo estima conveniente, podrá convocar una fase de audiencia pública a los interesados, en el caso de que existan proyectos que se solapen o cuando la suma de las potencias solicitadas superen el límite establecido por el operador del sistema o gestor de la red de transporte en la caracterización de área eólica marina, con el fin de que los solicitantes puedan, en el plazo de un mes, modificar sus propuestas o presentar una propuesta conjunta eliminando así el solapamiento o reduciendo sus potencias hasta el límite máximo establecido. En este caso, no podrá modificarse al alza la oferta económica propuesta por cada uno de los solicitantes $\mathrm{y}$, en el caso de presentación de una propuesta conjunta, la oferta económica se calculará ponderando las ofertas de los solicitantes iniciales, de acuerdo a su porcentaje de participación en la

Ministerio de Medio Ambiente, un representante con rango de Subdirector General designado por la Dirección General para la Diversidad del Ministerio de Medio Ambiente, el Subdirector General de Seguridad Marítima y Contaminación del Ministerio de Fomento, un representante con rango de Subdirector General designado por la Dirección General de Recursos Pesqueros del Ministerio de Agricultura, Pesca y Alimentación, un representante del Instituto Español de Oceanografía (IEO), un representante del Instituto para la Diversificación y Ahorro de la Energía (IDAE), un representante con rango de Subdirector General designado por la Dirección General de Desarrollo Industrial del Ministerio de Industria, Turismo y Comercio, un representante designado por la Consejería con competencias en materia de energía de cada una de las CCAA y Ciudades Autónomas que linden con el Área Eólica Marina, actuando como Secretario, con voz pero sin voto, un funcionario adscrito a la Subdirección General de Energía Eléctrica. Téngase en cuenta, a día de hoy, la nueva estructura de los Ministerios a que se hace referencia, concretamente el Ministerio de Industria, Turismo y Comercio, el Ministerio de Medio Ambiente y Medio Rural y Marino y el Ministerio de Fomento. 
sociedad o sociedades promotoras de la propuesta conjunta. Así, el porcentaje máximo de ponderación de la oferta más alta será del 75 por 100 .

Los criterios a tener en cuenta por parte del Comité de valoración para evaluar las solicitudes presentadas, serán los siguientes (art. 16): “a) Capacidad legal suficiente, técnica y económica del promotor del proyecto. b) Potencia máxima a instalar determinada en la caracterización de área, tendrá carácter limitativo, por lo que habrá que tener en cuenta las potencias de instalaciones para las que se haya resuelto un procedimiento de concurrencia y se encuentren en fase de funcionamiento o de estudio.

c) Oferta de prima presentada. d) Previsión de horas equivalentes de funcionamiento de la instalación en función de los datos disponibles en el momento de efectuar la solicitud. e) Tecnología a utilizar en el proyecto y su repercusión en la estabilidad del sistema eléctrico. f) Impacto económico, medioambiental y social asociado al proyecto. g) Potencia a instalar por cada proyecto, teniendo en cuenta la distribución racional de los aerogeneradores con el fin de lograr la máxima potencia posible en función de la extensión del proyecto. h) Impacto sobre la seguridad en la navegación, en las rutas marítimas y en la salvaguardia de la vida humana en el mar y otros criterios que hayan sido publicados en el anuncio en el que se convocó la apertura del procedimiento de concurrencia".

El Comité de valoración también podrá fijar un límite máximo de prima por encima del cual los proyectos quedarán desestimados.

Como señalábamos supra, el Comité de Valoración efectuará la propuesta de resolución en el plazo de tres meses desde la finalización del período de recepción de solicitudes, que será elevada a la Secretaría general de la Energía para la resolución final del procedimiento de concurrencia, antes de que transcurra un mes desde a formulación de la propuesta.

Francisco DELGADO PIQUERAS ha advertido varias consideraciones críticas en torno al establecimiento de un procedimiento de concurrencia en este ámbito. Así, denuncia la falta de cobertura legal del sometimiento de las solicitudes de los interesados a un procedimiento de concurrencia, no previsto ni en la Ley del Sector Eléctrico ni en la Ley de Costas. Precisa que, aun siendo cierto que el art. 75 de la LC admite que la Administración pueda convocar concursos para el otorgamiento de concesiones y autorizaciones en este dominio, se trata de una previsión genérica que tendría que estar 
justificada en alguna de las razones materiales que permiten sustituir el sistema de autorización, que es el procedente como regla general ${ }^{32}$.

Como es sabido, las normas ordenadoras de las actividades, así como las reguladoras de los bienes de dominio público, positivan la autorización, la concesión y demás títulos habilitantes para su ejercicio, ocupación y/o utilización, como técnicas jurídicas que permiten controlar el cumplimiento del ordenamiento jurídico. Estas técnicas sirven para remover los obstáculos que limitan el ejercicio de actividades intervenidas, por afectar al interés general o a la utilización u ocupación de bienes de dominio público. En el caso que nos ocupa, en puridad no se trata de someter a concurrencia, en aplicación de las posibilidades que el legislador de Costas otorga a la Administración del Estado ex art. 75 de la LC, una concesión de ocupación del dominio público marítimo-terrestre, sino de someter a dicho procedimiento de concurrencia la atribución del derecho de la reserva de zona correspondiente a la poligonal para la cual se presentó el proyecto inicial, por un período de dos años, con carácter de exclusividad. Será entonces cuando de oficio se remitirá toda la documentación a la autoridad competente en materia de costas para tramitar la solicitud de ocupación del dominio público marítimo-terrestre. En este caso, desde luego, no tendría sentido que la Administración convocara concurso para el otorgamiento de esta concesión, pues el adjudicatario o concesionario podría resultar una persona distinta a la que obtuvo el derecho de reserva de zona, a pesar de los términos del art. 75 de la LC, que resultaría de aplicación.

\subsection{Resolución del procedimiento de reserva de zona. Su impugnación}

Recapitulando todo lo anterior, una vez considerados los criterios indicados supra, el Comité de Valoración elevará la Propuesta de Resolución al Secretario de Estado de Energía para su consideración antes de que transcurran tres meses desde la finalización del período de recepción de solicitudes, quien dictará Resolución antes de que transcurra un mes desde la fecha de la Propuesta.

En nuestra opinión, y aunque no se establezca expresamente, la resolución del órgano competente, esto es, del Secretario de Estado de Energía, podrá apartarse del sentido de la propuesta de resolución elevada por el Comité de Valoración, motivando esta

\footnotetext{
${ }^{32}$ DELGADO PIQUERAS, F., "Naturaleza jurídica de la energía eólica”, en Torres López, Arana García, Energía eólica... cit., p. 241.
} 
circunstancia, en los supuestos en que el órgano competente llegue a otra conclusión bien de la aplicación de los criterios a que se refiere el art. 16 del RD 1028/2007, o en los casos de fuerza mayor, modificación normativa de cuya aplicación resulte contrario a la norma el sentido de la propuesta, en supuestos de desistimiento de algún o algunos solicitantes o por cualquier otra causa de interés público debidamente justificada ${ }^{33}$.

Finalmente, la resolución del procedimiento de concurrencia y otorgamiento de la reserva de zona será notificada a los interesados y publicada en el BOE y en el Boletín Oficial de la Provincia o Provincias afectadas por el proyecto en el plazo de un mes desde la fecha de la misma (art. 17 Real Decreto 1028/2007). Sobre esta sucesión de plazos, un mes para la resolución desde la formulación de la propuesta y un mes para notificar y publicar la resolución, ALENZA GARCÍA ha formulado serias críticas, por considerar que se trata de una regulación contraria a la LRJPAC, ofreciendo una interpretación conforme con el art. 43 de la misma, según la cual el plazo de resolución y notificación sería de un mes, aunque la Administración dispondría del plazo de un mes para la publicación oficial.

Por lo que se refiere al contenido de la Resolución, esta hará referencia a los siguientes aspectos. En primer lugar, indicará el proyecto o proyectos seleccionados por el Comité de Valoración de entre las solicitudes presentadas, con referencia a su promotor o promotores y un resumen de sus características ${ }^{34}$. En segundo lugar, justificará dicha selección con base en los criterios contemplados en el art. 16 del Real Decreto 1028/2007 y en los criterios adicionales que, en su caso, se hayan establecido. Por último, llevará a cabo una atribución, para cada uno de los solicitantes seleccionados, del derecho de la reserva de zona correspondiente a la poligonal para la cual se presentó el proyecto, por un período de dos años, con carácter de exclusividad. De acuerdo con el

\footnotetext{
${ }^{33}$ En sentido contrario, ALENZA GARCÍA, "La autorización de parques eólicos marinos" cit., p. 512, según el cual el Real Decreto 1028/2007 no alude a motivo alguno que permita al secretario general de la Energía dictar un resolución en un sentido divergente con la propuesta.

${ }^{34}$ En virtud del art. 18 del Real Decreto 1028/2007, los avales depositados por los solicitantes que no resulten elegidos en el procedimiento de concurrencia, serán devueltos al finalizar el mismo. No obstante, si con anterioridad a la resolución del procedimiento de concurrencia y otorgamiento de la reserva de zona, alguno de los promotores desiste voluntariamente de la tramitación de su proyecto o no responde a los requerimientos de información o actuación en el plazo de tres meses, se procederá a la ejecución del aval.
} 
art. 18 del Reglamento, el solicitante que haya obtenido la reserva de zona deberá depositar un aval adicional por importe del 1 por 100 del presupuesto de su proyecto ${ }^{35}$.

Asimismo, con la resolución del procedimiento de concurrencia se le otorgará al solicitante o solicitantes seleccionados un derecho de acceso a la red de transporte por la potencia asignada en dicha resolución, que podrá ser revocado en el caso de no llevarse a cabo la instalación en los términos previstos. De dicha resolución se enviará copia a la Dirección General de Calidad y Evaluación Ambiental para iniciar la evaluación de impacto ambiental del proyecto, junto con la información necesaria ${ }^{36}$, aportada por el promotor, para llevar a cabo dicho trámite; a la Dirección General de Costas, para tramitar el procedimiento de concesión para la ocupación del dominio público marítimo-terrestre cuando se cumpla con todos los requisitos exigidos por la Ley 22/1988, de 28 de julio, de Costas; y a la Dirección General de Marina Mercante. Por su parte, el art. 17 in fine del Real Decreto 1028/2007 establece que contra la resolución del procedimiento de concurrencia y otorgamiento de la reserva de zona podrá interponerse recurso de alzada ante el Ministerio de Industria, Turismo y Comercio.

Resta por referirnos en esta sede a los supuestos en que el órgano competente no resolviera y notificara la resolución en plazo, en cuyo caso se entenderá desestimada la solicitud, de conformidad con la disposición adicional tercera de la Ley 54/1997, del Sector Eléctrico ${ }^{37}$. Ahora bien, ¿cuál es la duración del procedimiento? El Real Decreto no señala nada al respecto, de manera que, en principio, habría que entender que resultaría de aplicación el plazo de tres meses a que se refiere el art. 42 de la LRJPAC. Sin embargo, de los distintos plazos que establece el Real Decreto para los distintos trámites que conforman el procedimiento puede comprobarse que dicho plazo de tres meses no sería suficiente para dar cumplimiento a todos ellos. En efecto, de la lectura detenida del art. 17 del Real Decreto 1028/2007 puede deducirse que el plazo máximo

\footnotetext{
${ }^{35}$ Así, una vez obtenga la autorización administrativa para la instalación, ambos avales le serán devueltos. Con los depósitos de estos avales, se alcanzará el 2 por 100 del presupuesto del proyecto, cumpliendo así con la fianza provisional exigida en el punto 1 del art. 88 de la Ley 22/1988, de 28 de julio, de Costas ${ }^{35}$, así como los avales regulados en los arts. 124 ó 59 bis o, en su caso, 66 bis del Real Decreto 1955/2000, de 1 de diciembre.

${ }^{36}$ De acuerdo con el art. 8 del presente Real Decreto, la información necesaria para iniciar la evaluación ambiental del proyecto será una acreditación de la capacidad del solicitante, una memoria resumen, un anteproyecto de la instalación de generación eólica marina y una separata para las AAPP.

37 En virtud de esta disposición, las solicitudes de resoluciones administrativas que deban dictarse conforme a lo dispuesto en esta Ley se podrán entender desestimadas si no recae resolución expresa en el plazo que al efecto se establezca en sus disposiciones de desarrollo.
} 
para dictar la resolución del procedimiento de concurrencia es de cuatro meses, contados a partir del día siguiente a aquel en que finaliza el plazo para presentar solicitudes. Transcribimos a continuación el texto del art. 17 del Real Decreto 102872007 para una mejor comprensión de esta cuestión:

“El Comité de valoración elevará la propuesta de resolución al Secretario General de Energía para su consideración antes de que transcurran tres meses desde la finalización del periodo de recepción de solicitudes, quien dictará resolución antes de que transcurra un mes desde la fecha de la propuesta. Dicha propuesta deberá ser motivada conforme a los criterios indicados en el artículo 16. La resolución del procedimiento de concurrencia y otorgamiento de la reserva de zona serán notificados a los interesados y enviados al Boletín Oficial del Estado para su publicación, en el plazo de un mes desde la fecha de la misma.

En la resolución se hará mención, en particular, a los siguientes extremos: a) Indicación del proyecto o proyectos seleccionados por el Comité de valoración de las solicitudes, con referencia a su promotor o promotores y un resumen de sus características. b) Justificación de dicha selección con base en los criterios determinados en el artículo 16 de este Real Decreto y, en su caso, a los criterios adicionales que se hayan establecido previamente. c) Atribución, para cada uno de los solicitantes seleccionados, del derecho a la reserva de la zona correspondiente a la poligonal para la cual se presentó el proyecto, por un periodo de dos años, con carácter de exclusividad.

La resolución del procedimiento de concurrencia otorgará al solicitante o solicitantes seleccionados un derecho de acceso a la red de transporte por la potencia que le sea asignada en dicha resolución, sin perjuicio de que dicho derecho pueda ser revocado de no llevarse a cabo la instalación en los términos previstos.

La resolución deberá publicarse en el Boletín Oficial del Estado y en el Boletín Oficial de la provincia o provincias afectadas por el proyecto. Además deberá ser notificada al solicitante.

De la resolución se enviará copia a la Dirección General de Calidad y Evaluación Ambiental, para la iniciación de la evaluación de impacto ambiental del proyecto, de acuerdo con lo preceptuado en el Real Decreto Legislativo 1302/1986, de 28 de junio, de evaluación del impacto ambiental y su normativa de desarrollo, acompañando la información necesaria para este trámite, previamente aportada por el promotor, de acuerdo con el artículo 8 del presente Real Decreto, a la Dirección 
General de Costas, para la tramitación del procedimiento de concesión para la ocupación del dominio público marítimo-terrestre, una vez constatado el cumplimiento de todos los requisitos exigidos por la Ley 22/1988, de 28 de julio, de Costas, y su Reglamento, y a la Dirección General de Marina Mercante.

Contra la resolución del procedimiento de concurrencia y otorgamiento de la reserva de zona podrá interponerse, conforme a lo dispuesto en la Ley 30/1992, de 26 de noviembre, recurso de alzada ante el Ministro de Industria, Turismo y Comercio".

Como puede comprobarse, la duración del procedimiento de concurrencia resulta ser, como máximo, de cuatro meses. Pero, ¿cuál es la duración del procedimiento de reserva de zona? Se trata de una laguna de regulación importante que, además, va a generar indefensión al solicitante inicial, que desconocerá el momento a partir del cual puede interponer el correspondiente recurso de alzada frente a la desestimación, cuando no exista resolución administrativa expresa. Además, el procedimiento de reserva de zona es un procedimiento que se inicia a instancia de parte, en el que se inserta un procedimiento de concurrencia que se inicia de oficio que podría caducar, pudiendo a la vez tener lugar los efectos del silencio administrativo respecto del procedimiento de reserva de zona para el promotor inicial (arts. 42 y 43 de la LRJPAC).

\section{Derechos y obligaciones del beneficiario de la reserva de zona}

El solicitante que resulte elegido como titular de la reserva de zona tendrá la facultad de realizar las tareas de investigación correspondientes en el área determinada y estará obligado a proporcionar a los distintos órganos de la Administración, la información que le soliciten en relación a las características de la investigación que se lleve a cabo y a los trabajos, producciones e inversiones que se realicen, así como cualquier informe relativo a la investigación del recurso eólico que resulten de sus competencias. Estos datos facilitados por el titular de la reserva serán confidenciales y no podrán ser comunicados a terceros sin autorización expresa del titular durante la vigencia del derecho a la reserva de zona $^{38}$. El Real Decreto 1028/2007 crea el Registro de reservas

\footnotetext{
${ }^{38}$ En el caso de que el desistimiento del promotor venga provocado por la insuficiencia de recurso eólico, en función de su estudio de viabilidad, deberá presentar a la DGPEM los datos obtenidos de sus investigaciones durante el período de reserva de zona, quien podrá determinar la devolución del aval correspondiente al 1 por 100 del presupuesto. Cuando esto ocurra, la DGPEM incorporará los datos remitidos al documento de caracterización de área eólica marina que corresponda, pasando estos datos a tener carácter público.
} 
de zona como registro público especial adscrito al Ministerio de Industria, Turismo y Comercio, donde se hará constar la identidad del beneficiario de la reserva de zona, el día de la presentación de su solicitud, la fecha de resolución, el número de orden que le haya correspondido y otros aspectos relativos a la reserva de zona.

El derecho que confiere el otorgamiento de la reserva de zona tendrá una vigencia de dos años como máximo, prorrogable un año más cuando existan circunstancias imputables al funcionamiento de la Administración o causas de fuerza mayor y que serán valoradas por la DGPEM a petición del interesado y previo informe de la Dirección General de Costas. La DGPEM, a través de la Comisión Nacional de la Energía, será la encargada de realizar la inspección en relación al cumplimiento de las condiciones técnicas y económicas que resulten exigibles al beneficiario de la reserva de zona $^{39}$. Para el desarrollo de las actividades constructivas asociadas a los trabajos de investigación, además del otorgamiento de la reserva de zona, que incorporará la correspondiente DIA, es necesario obtener el título de ocupación del dominio público marítimo-terrestre o portuario que proceda, según lo dispuesto en la Ley 22/1988, de 28 de julio, de Costas y su Reglamento, o en la legislación reguladora del dominio público portuario (art. 22). Resulta llamativo que se haga referencia a la ocupación del dominio público portuario, cuando el Reglamento sólo se aplica con carácter general al MT, no haciéndose en ningún otro lugar referencia la ubicación de los parques eólicos marinos en aguas interiores o en dominio público portuario. Por otra parte, al beneficiario de la reserva de zona que obtenga el título de ocupación del dominio público marítimoterrestre se le atribuye, con carácter de exclusividad, la facultad de realizar las operaciones de investigación del recurso eólico en la poligonal correspondiente. Este título de ocupación es imprescindible para proceder a la instalación de la torre de medición, la instalación meteorológica o el puesto de observación, y sólo se podrá obtener una vez declarada la correspondiente reserva de zona.

\section{Régimen jurídico de los avales previstos en el Real Decreto 1028/2007}

El Real Decreto 1028/2007 regula dos avales en los arts. 14 y 18. El primero se exige a todos los interesados en participar en el procedimiento de concurrencia y el segundo

\footnotetext{
${ }^{39}$ El art. 19 del Real Decreto 1028/2007 remite a la disposición adicional undécima de la Ley 54/1998, de 7 de octubre, del Sector de Hidrocarburos, donde se detallan las funciones de la Comisión Nacional de la Energía, y debe aludir, como es sabido, a la Ley 34/1998, pues se trata de una errata.
} 
exclusivamente al promotor o promotores elegidos. Ambos deberán efectuarse por el importe del 1\% del presupuesto de la instalación, respectivamente. Téngase en cuenta, no obstante, que el primero de ellos deberá calcularse sobre el presupuesto de la instalación de estudio del área, y no sobre el presupuesto de la instalación final. Con la formalización de ambos se entiende que los promotores elegidos cumplirán con la fianza prevista en el art. 88.1 de la LC. Una vez obtenida la concesión correspondiente, éstos estarán obligados a constituir una fianza del 5\%, para dar cumplimiento al art. 88.3 de la misma LC, lo cual, en nuestra opinión no tiene mucho sentido, ya que debería haberse establecido en el Real Decreto la obligación de ampliar la cuantía del aval del $2 \%$ al $5 \%$ una vez que el promotor obtiene la concesión de ocupación de dominio público.

Por otra parte, el Real Decreto 1028/2007 regula seis supuestos en los que tendrá lugar la ejecución del aval o avales depositados por los promotores de las instalaciones de energía eólica marina ${ }^{40}$. Y, en segundo lugar, el art. 18 regula dos supuestos en los que tendrá lugar la devolución del aval a que refiere el art. 14 del Real Decreto 1028/2007. Esta devolución se producirá en los casos en que los solicitantes de la reserva de zona no sean elegidos tras la tramitación del procedimiento de concurrencia. El segundo podrá tener lugar, si así lo decide la DGPEM, en supuestos de desistimiento del promotor provocado por la insuficiencia de recurso eólico, en función de su estudio de viabilidad $^{41}$.

\section{Procedimiento de autorización de la instalación}

El procedimiento de autorización de la instalación se inicia con la presentación de la solicitud del promotor, antes de la finalización de la vigencia de la reserva de zona, que como recordaremos, con carácter general, será de dos años. La solicitud se realizará

\footnotetext{
${ }^{40}$ Desistimiento voluntario de la tramitación del proyecto anterior a la resolución del procedimiento de reserva de zona (ejecución del primer aval), incumplimiento del depósito del segundo aval (ejecución del primer aval), desestimación de la modificación de la oferta de prima (ejecución del primer aval), incumplimiento de la obligación de desmantelamiento de la instalación y restitución del dominio público -en función del plan de inversiones y del plan de restauración presentados- (ejecución de los dos avales), incumplimiento del pago de multas y sanciones (ejecución de los dos avales) y desestimación de la solicitud de autorización por incumplimiento de las obligaciones derivadas de la normativa aplicable (ejecución de los dos avales).

${ }^{41}$ En estos casos, el promotor deberá presentar a la DGPEM los datos obtenidos de sus investigaciones durante el período de reserva de zona. Cuando esto ocurra, la DGPEM incorporará los datos remitidos al documento de caracterización de área eólica marina que corresponda, pasando estos datos a tener carácter público.
} 
según lo dispuesto en el art. 122 del Real Decreto 1955/2000, de 1 de diciembre y será dirigida a la Dirección General de Política Energética y Minas (DGPEM). El interesado debe acompañar a la misma la documentación exigida en los apartados 3, 4 y 5 (sic) del art. 8 del Real Decreto 1028/2007. Según el art. 25.1.a del Reglamento, si dicha documentación ya hubiera sido presentada, se aportarán las modificaciones y adiciones que resultaran procedentes. Resulta imposible que no hubiera sido presentada, pues el art. 8 contiene la documentación que ha de acompañarse a la solicitud de reserva de zona, procedimiento que, en todo caso, deberá tramitarse con carácter previo al procedimiento de autorización de instalación ${ }^{42}$. Añade el precepto que cuando la reserva de zona hubiera sido objeto del procedimiento de concurrencia, se podrá solicitar la modificación de la superficie solicitada inicialmente y aprobada por la resolución que pusiera fin al procedimiento de concurrencia, advirtiendo que cuando se trate de un incremento de superficie, esta ampliación deberá ser aprobada por el Consejo de Ministros. No queda claro si es que puede darse el caso de que no tenga lugar la apertura del procedimiento de concurrencia (art. 14), por lo que parece no tener demasiado sentido dicha precisión, y entendemos que en todo caso podrá tener lugar la solicitud de modificación de la superficie inicial.

De igual modo, podrá solicitarse la modificación de la potencia inicialmente establecida, siempre que no supere el margen de hasta un 15 por 100 superior o inferior a la inicial, debiendo ser ésta en todo caso superior a $50 \mathrm{MW}^{43}$ (art. 25.1.a). Las instalaciones de potencia no superior a 50 MW serán incluidas en el régimen especial y las de potencia superior en el ámbito de aplicación del art. 45 del Real Decreto $661 / 2007^{44}$. En segundo término, el promotor deberá acompañar a la solicitud, en todo

\footnotetext{
${ }^{42}$ Cfr. LÓPEZ SAKO, Regulación y autorización... cit. pp. 529-530.

${ }^{43} \mathrm{La}$ doctrina ha discutido el establecimiento de este límite mínimo, al igual que el límite máximo establecido para el régimen especial. Cfr. LóPEZ SAKO, M. J. cit, pág. 514. Téngase en cuenta, no obstante, la disp. final $2^{\mathrm{a}}$ del Real Decreto 1028/2007, que habilita al Ministro de Industria, Turismo y Comercio para modificar dicho límite al alza o a la baja.

44 El apartado primero de la Disp. Final Segunda del Real Decreto 1028/2007 habilita al Ministro de Industria, Turismo y Comercio para modificar, hasta en un 20 por ciento al alza o a la baja, el límite de 50 MW establecido en el párrafo tercero del artículo 2, para un proyecto o proyectos particulares. Asimismo, la disposición final 2 establece que se habilita al Ministro de Industria, Turismo y Comercio para permitir las autorizaciones administrativas de instalaciones de generación eólicas marinas de potencia inferior o igual a $10 \mathrm{MW}$, cuando tengan por finalidad la investigación, desarrollo, innovación y demostración de tecnología aplicada a la generación eólica marina, pudiendo exigir los requisitos técnicos y geográficos que se estimen pertinentes con el fin de salvaguardar el carácter diferenciador de la instalación autorizada con respecto a una instalación de generación eléctrica con fines comerciales. En este caso, se establece un procedimiento simplificado que comienza con la solicitud de autorización
} 
caso, el Proyecto y estudio de impacto ambiental de la instalación (art. 25.1.b). En tercer lugar, deberá acompañar la solicitud de inclusión de la instalación en el régimen regulado en el Real Decreto 661/2007, de 25 de mayo, incluyendo la prima necesaria de la energía producida. Finalmente, y a efectos de información pública, deberá presentarse de nuevo la información a que hace referencia el art. 8 en el caso de que hayan tenido lugar modificaciones que afecten a su contenido y el proyecto para la ocupación del dominio público marítimo-terrestre (art. 25.2)

La solicitud será sometida a un único trámite de información pública, referida a la autorización de la instalación, al estudio de impacto ambiental de la misma y a la concesión del dominio público marítimo-terrestre. Este trámite de información pública, así como las alegaciones, la información a otras Administraciones públicas y su resolución se harán de conformidad con los arts. 125, 126, 127 y 128 del Real Decreto 1955/2000 (art. 27).

Para el adecuado seguimiento del procedimiento, con carácter previo a la autorización de la instalación de generación eólica marina y a la concesión del dominio público marítimo-terrestre, el proyecto tendrá que someterse a una evaluación de impacto ambiental $^{45}$.

Finalmente, la DGPEM resolverá y notificará la resolución antes de que transcurran 45 días desde la declaración de impacto ambiental, remitiendo una copia de dicha resolución a la Dirección General de Costas. Asimismo, una vez realizada dicha DIA, la tramitación de la concesión de ocupación del dominio público marítimo-terrestre se realizará de acuerdo a lo establecido en la Ley 22/1988, de 28 de julio, de Costas y será competencia de la Dirección General de Costas resolver, a la vista de la declaración de impacto ambiental y de la resolución del procedimiento de autorización de la instalación efectuada por la Dirección General de Política Energética y Minas. Esta concesión de ocupación del dominio público marítimo-terrestre requerirá la autorización de la Dirección General de la Marina Mercante del Ministerio de Fomento, cuando puedan verse afectadas la seguridad marítima, la navegación y/o la vida humana en el mar.

administrativa regulada en el artículo 24 del presente real decreto, y que será regulado con carácter subsidiario de acuerdo con el Real Decreto 1955/2000.

45 Según lo preceptuado en el Real Decreto Legislativo 1302/1986, de 28 de junio, de Evaluación de Impacto Ambiental y normativa de desarrollo. Hoy esta remisión ha de entenderse efectuada al Real Decreto Legislativo 1/2008, de 9 de enero, de EIA. 
Por último, debe señalarse que, en virtud del art. 70 de la Ley 22/1988, de Costas, las concesiones de dominio público no serán transmisibles intervivos, salvo algunas excepciones entre las que no se encuentran las instalaciones de energía eólica en el mar. En nuestra opinión, debería modificarse dicho art. 70 en el sentido apuntado.

Para concluir, debe advertirse que después de seguir este tortuoso procedimiento, en virtud del art. 111 del Real Decreto 1955/2000, además de la autorización de la instalación con la correspondiente EIA y demás títulos para la ocupación del dominio público marítimo-terrestre, será necesario que la Administración apruebe el proyecto de ejecución de la instalación y conceda la autorización de explotación.

\section{CUESTIONES CRÍTICAS QUE PLANTEA EL RÉGIMEN JURÍDICO VIGENTE}

A lo largo del presente estudio han sido puestas de manifiesto varias incoherencias que plantea la regulación que el Real Decreto 1028/2007 confiere al procedimiento de autorización de los parques eólicos marinos. Dedicamos ahora los presentes epígrafes a plantear las limitaciones del Estudio Estratégico Ambiental del litoral español que, desde su aprobación, preexiste a las eventuales solicitudes que se presenten, aunque sin obviar, como advierte Javier SANZ LARRUGA las virtualidades del mismo como punta de lanza de una nueva perspectiva de actuación más respetuosa con el orden constitucional de competencias $^{46}$. Asimismo, formularemos propuestas de lege ferenda para el replanteamiento de la regulación de las instalaciones eólicas en el mar.

\section{La problemática derivada del desfase del Estudio Estratégico Ambiental del} litoral español y del carácter parcial del Real Decreto 1028/2007. Hacia una verdadera planificación integrada del mar

Uno de los problemas que plantea el EEALE es el eventual desfase del mismo que pueda derivarse del desarrollo de políticas ambientales, piénsese en la declaración de áreas marinas protegidas (art. 32 de la Ley $42 / 2007)^{47}$, en la protección del patrimonio

\footnotetext{
${ }^{46}$ SANZ LARRUGA, "Los parques marinos en el marco..." cit., p. 373.

${ }^{47}$ A este respecto, también debe observarse que la Ley 41/2010, de protección del medio marino, prevé en su art. 5.1.d., los criterios de planificación del medio marino, señalando que el Gobierno podrá estableces directrices comunes a todas las estrategias en aspectos comunes como los aprovechamientos energéticos situados en el medio marino.
} 
cultural, o en el ejercicio de otros sectores económicos como la pesca, que puedan incidir en la aptitud para la instalación de parques eólicos marinos. También dicho desfase puede producirse por el desarrollo de nuevas tecnologías menos agresoras, como lo son, en principio, los parques eólicos flotantes, que exigen una reconsideración de las zonas aptas para estos usos. En tercer lugar, no debemos descartar que la evolución ecológica de los hábitats y especies asociadas, o los resultados de los estudios ecológicos de los mismos pueda exigir modificaciones en las poligonales inicialmente previstas en el EEALE. Finalmente, como es sabido, las instalaciones eólicas marinas tienen la virtualidad de funcionar como arrecifes artificiales, lo cual puede coadyuvar a la regeneración piscícola, por lo que sería posible concluir, con el respaldo de los estudios pertinentes, que las reservas pesqueras, que fundamentan de conformidad con el EEALE la exclusión de estas instalaciones en el ámbito de las mismas, son lugares idóneos para la ubicación de los parques eólicos marinos.

En estos supuestos, en los que quede en evidencia la necesidad de puesta al día del EEALE, la Administración, caso por caso, deberá decidir sobre la prevalencia de los distintos intereses en juego. En este sentido, no debieran resultar vinculantes los contenidos del Estudio en relación a la admisión a trámite la solicitud del promotor, y me refiero a las eventuales solicitudes que afectaran a zonas no aptas según el EEALE, ya que de los trabajos e investigaciones desarrolladas podría llegarse a una conclusión diversa. No obstante, dicho documento prevé la posibilidad de su revisión cuando se produzcan cambios significativos que afecten al diagnóstico ambiental descrito en el mismo EEALE, y se considere que dicha revisión permita un mejor cumplimiento de los objetivos de protección ambiental también contemplados ${ }^{48}$. Como puede deducirse, lo que sí es cierto es que el Estudio estratégico confiere cierta prevalencia a estos objetivos ambientales de protección sobre otros posibles intereses en juego.

Además de estas previsiones de revisión, debe tenerse en cuenta que cuando el desarrollo de las políticas a que nos referíamos se concrete en instrumentos vinculantes, esto es, en nuevas prohibiciones o limitaciones, como puede ser el caso de declaración de áreas marinas protegidas en aplicación de la normativa sobre espacios naturales, debería contemplarse su obligatoria adaptación. En este sentido, resulta interesante la previsión de Ley 41/2010, de 29 de diciembre, de Protección del medio marino, respecto de los denominados Programas de seguimiento que elaborará el Ministerio con

\footnotetext{
${ }^{48}$ Cfr. pág. 73 del EEALE.
} 
competencias en materia ambiental para evaluar permanentemente el estado medioambiental de las aguas marinas (art. 10). En efecto, con la aprobación de la LPMM, hemos asistido al nacimiento de una estrategia de planificación sectorial por demarcaciones marinas. A tales efectos, el medio marino español queda dividido en una serie de regiones y éstas, a su vez, subdivididas en las denominadas demarcaciones marinas: la del Estrecho y Alborán ${ }^{49}$, la Levantino balear ${ }^{50}$, la Noratlántica y la Sudatlántica.

Esta acertada división en distintas demarcaciones permite, desde luego, una planificación relativamente eficaz e integrada. No obstante, la efectividad práctica de la planificación es limitada en el terreno ambiental si no existen verdaderos instrumentos o técnicas de cooperación que garanticen un comportamiento homogéneo de los distintos actores con intereses en el mismo espacio. Es cierto que las estrategias marinas que se elaboren para cada una de las cuatro demarcaciones marinas constituyen, según el art. 7.1 de la LPMM, el marco general al que deben ajustarse necesariamente las diferentes políticas sectoriales y actuaciones administrativas con incidencia en el medio marino de acuerdo con lo establecido en la legislación sectorial correspondiente ${ }^{51}$. Hasta ahora no se ha aprobado ninguna de estas estrategias ${ }^{52}$. Asimismo, como apunta Javier SANZ

\footnotetext{
${ }^{49}$ Medio marino en el que España ejerce soberanía o jurisdicción comprendido entre el meridiano que pasa por el cabo de Espartel y una línea imaginaria con orientación $128^{\circ}$ respecto al meridiano que pasa por el cabo de Gata, y medio marino en el que España ejerce soberanía o jurisdicción en el ámbito de Ceuta, Melilla, las islas Chafarinas, el islote Perejil, Peñones de Vélez de la Gomera y Alhucemas y la isla de Alborán.

${ }^{50}$ Aquel espacio marino en el que España ejerce soberanía o jurisdicción comprendido entre una línea imaginaria con orientación $128^{\circ}$ respecto al meridiano que pasa por el cabo de Gata, y el límite de las aguas jurisdiccionales entre España y Francia en el Golfo de León.

${ }^{51}$ Respecto de la secuencia de tareas a seguir podremos decir que en un primer momento debe evaluarse inicialmente el estado del medio marino, que incluye las características naturales, las presiones e impactos y un análisis económico y social de la utilización del medio marino y de los costes de su deterioro. La segunda tarea es la determinación del buen estado ambiental, que como sabemos se debe basar en una serie de descriptores ya comentados en el anterior punto. La tercera es el establecimiento de una serie de objetivos ambientales, que deben ser, en medida de lo posible, mensurables, operativos, coherentes entre ellos y con las demás áreas marinas, considerados de forma socioeconómica y enfocados a lograr el buen estado ambiental que previamente se ha definido. Simultáneamente, se deben definir una serie de indicadores para poder evaluar la consecución de los objetivos ambientales. Precisamente es en este punto donde reside el vínculo más estrecho que pueda establecerse con un área marina protegida, ya que los programas de medidas podrán incluir medidas específicas para la protección de especies y tipos de hábitats pudiendo por tanto incluir el establecimiento de AMPs. La cuarta tarea es el establecimiento de un programa de seguimiento para evaluar permanente medio el estado del medio. Por último, se debe elaborar y aplicar un programa de medidas para lograr el buen estado ambiental. Una vez completadas todas las tareas de la estrategia marina, será aprobada mediante un Real Decreto, previo informe a los Ministerios afectados. No obstante, todas estas tareas tendrán una actualización cada seis años, pudiendo ser modificadas si existe la necesidad de variar los objetivos planteados.
}

${ }^{52}$ A través de una nota de prensa, la Secretaria de Estado de Cambio Climático informo el pasado 23 de marzo de 2011 sobre el desarrollo de las estrategias marinas. Puede encontrase información al respecto en 
LARRUGA, la Estrategia Española sobre Gestión Integrada del Litoral debería cohonestarse con la futura estrategia de protección del medio marino ${ }^{53}$.

Por otra parte, el régimen jurídico derivado del Real Decreto 1028/2007 es parcial, en el sentido de que puede o no resultar de aplicación a otras zonas marítimas, en función de la decisión discrecional, casi "arbitraria”, de la Administración competente, en este caso y en concreto, el Ministerio de Industria Turismo y Comercio ${ }^{54}$. En nuestra opinión, debería regularse en una misma norma el tratamiento jurídico dispensado a estas instalaciones, tanto fijas como flotantes, y en cualquiera de las zonas sobre las que la jurisdicción del Estado nos permita su regulación. También sería conveniente trabajar en la protección de la biodiversidad más allá de la jurisdicción de los Estados, para alcanzar, al menos, el objetivo común de aplicar la EIA ${ }^{55}$.

Por otra parte, no está resuelta la problemática derivada de la coexistencia de planes que afecten a una misma área marina, problemática que tantos quebraderos de cabeza ha suscitado en el ámbito del territorio. Aunque el EEALE, a la hora de declarar las distintas zonas aptas, de exclusión y aptas con condicionantes ambientales, ha tenido en cuenta estos planes - como los planes integrales de gestión para la conservación de recursos pesqueros o los planes nacionales de arqueología subacuática-, el desarrollo ulterior de otras políticas — como la protección del patrimonio cultural—o de otros sectores económicos — como la pesca— pueden colisionar con la aptitud o los limitados condicionantes de determinadas zonas previstos en el EEALE. En estos supuestos, como señalábamos supra, la Administración, caso por caso, deberá decidir sobre la

en http://ascienciasdelmar.blogspot.com/2011/03/la-evaluacion-de-las-demarcaciones.html Durante el verano de 2011se creó una Comisión Interministerial de Estrategias Marinas para la elaboración, aplicación y seguimiento y antes de fin de año está previsto que se cree un Comité de Seguimiento de la Estrategia Marina. Para el trabajo de evaluación inicial se ha creado el "Grupo Español de Estrategias Marinas", que incluye técnicos de unidades del MARM, el Instituto Español de Oceanografía y el centro de Estudios de Puertos y Costas del CEDEX. De otra parte, se ha indicado que se espera tener un borrador para consulta de las diferentes administraciones, organizaciones y público en general con la evaluación inicial, la definición del buen estado ambiental y la propuesta de objetivos ambientales para las demarcaciones situadas en el Mar Mediterráneo en marzo 2012.

${ }^{53}$ SANZ LARRUGA, "Los parques marinos en el marco..." cit., p. 372.

${ }^{54}$ No obstante, el ámbito de estudio del EEAL abarca una banda litoral de aproximadamente 24 millas náuticas medidas desde la línea de base recta que sirve para medir el MT, incluyendo además las aguas interiores definidas. Esta banda es suficientemente amplia, según el Estudio, para abarcar la totalidad de los proyectos eólicos marinos previsibles actualmente, con el estado presente de la tecnología eólica marina comercial. Teniendo en cuenta que una milla náutica equivale a 1,852 metros, el estudio afecta a 44.448 metros.

${ }^{55}$ Cfr. NU Doc. A/61/65, de 20 de mayo de 2006 y UN Doc A/63/79, de 16 de mayo de 2008. Cfr. arts. $82,194.5$ y 196.1 de la CONVEMAR. 
prevalencia de los distintos intereses en juego, y siempre con riguroso respeto de la articulación de competencias en el Estado autonómico ${ }^{56}$. Por ello, también resulta conveniente seguir trabajando en este sentido, concretando los instrumentos formales de aprobación de los distintos planes y estrategias así como las relaciones entre los mismos.

Todo lo anterior, unido a la experiencia derivada de las desafortunadas consecuencias que la falta de ordenación territorial ha producido en el ámbito terrestre derivada del ejercicio de políticas urbanísticas, turísticas, agrícolas y ambientales, entre otras, todas ellas en gran parte descoordinadas, debería servir para comenzar a desarrollar una planificación global, por mares u océanos, justamente con la misma filosofía que las Gestión integrada del litoral, pero en relación a lo que se ha venido en denominar Aquitorio, como el espacio en el que los Estados ribereños, con alcance variable y de acuerdo con la división por zonas del mar de la CONVEMAR, pueden legítimamente desarrollar una política propia al amparo de su soberanía, que coincide con el desarrollo de todas o al menos de las más relevantes de las actividades que reclaman adecuada ordenación para evitar solapamientos, incompatibilidades y conflicto entre ellas. Finalidad ésta que reclama y, por ello, justifica el recurso a la planificación con perspectiva general $^{57}$. Con la misma filosofa integradora que inspira la Gestión Intergada de las Zonas Costeras (GIZs), la futura Ordenación del Espacio Marino (OEM), como disciplina equivalente a la ordenación del territorio en el ámbito terrestre, que afecta al lecho, a la columna de agua y a la superficie, necesariamente vinculante, debe ordenar los distintos usos del mar en cada uno de estos subespacios. El problema lo encontramos, prima facie, en la inexistencia, hasta la fecha, de planes de ordenación del mar vinculantes, como ocurre con los instrumentos de ordenación del territorio en tierra. Además, como consecuencia del carácter extrajurisdiccional de gran parte de los mares y océanos, resulta complicado determinar en el momento actual hasta dónde es posible la ordenación. En nuestro caso, el área marítima donde el Estado español puede incidir en la ordenación de los espacios marítimos es, además de en las aguas interiores -en las que, desde luego deberá respetar las competencias autonómicas-, en el Mar

\footnotetext{
${ }^{56}$ Un estudio pormenorizado de la articulación de competencias ambientales y conexas en el Estado autonómico puede consultarse en FERNÁNDEZ SALMERÓN, M., SORO MATEO, B., La articulación de competencias ambientales en el Estado autonómico, Atelier, 2001.

${ }^{57}$ PAREJO NAVAJAS, T., La proyección de la ordenación física de los usos sobre la costa y el Mar próximo: la planificación del aquitorio, Iustel 2011, p. 22.
} 
Territorial. Difícilmente, si atendemos a la CONVEMAR, podría afirmarse que esta planificación pudiera incidir en la Zona Contigua, en la Zona Económica Exclusiva y en la Plataforma Continental, lo cual no significa que ello no resulte aconsejable ${ }^{58}$.

En este sentido, y consciente de estas limitaciones, el Real Decreto 1028/2007, de 20 de julio, por el que se establece el procedimiento administrativo para la tramitación de las solicitudes de autorización de instalaciones de generación eléctrica en el Mar Territorial extiende su aplicación, en virtud de su disposición adicional 5, en principio, a la zona contigua y a la zona económica exclusiva; y decimos en principio porque señala expresamente que "podrá" ser de aplicación a la zona contigua y la zona económica exclusiva. Resulta lógico que se establezca esta eventualidad respecto de la Zona Contigua, en la que no existen más derechos soberanos que los que se derivan del art. 33 de la CONVEMAR. Además, resultaría de aplicación a esta zona el Convenio sobre la EIA en un contexto transfronterizo, respecto de actividades susceptibles de producir un impacto transfronterizo en una zona bajo jurisdicción de una de las partes, es decir, incluida la Zona Contigua, y que haya sido causado por una actividad propuesta cuyo origen físico esté ubicado total o parcialmente dentro de una zona situada bajo la jurisdicción de otra parte (art. 1.viii). Pero no nos parece tan lógico, en cambio respecto del régimen jurídico de las instalaciones de energía eólica marina que se pretendan ubicar en la ZEE, que deberán observar, además de los arts. 56 y 60 de la CONVEMAR, la Directiva 2008/56/CE, de 17 de junio de 2008, por la que se establece un Marco de acción comunitaria para la política del medio marino (Directiva marco sobre la estrategia marina), así como la reciente Ley 41/2010 LPMM, que se aplica también a la zona económica exclusiva en el cantábrico y en el atlántico, así como a la plataforma continental ampliada ${ }^{59}$. En consonancia con ello, y en nuestra opinión, debería ser el mismo el régimen jurídico autorizatorio aplicable en el Mar Territorial y en la Zona Económica Exclusiva. Además, debería regularse en la misma norma, pero atendiendo a las posibilidades competenciales de las CCAA, la instalación de los parques eólicos marinos en las aguas interiores ${ }^{60}$. En relación con esta última zona marina, junto con la problemática derivada del ámbito de aplicación de cada una de las políticas que inciden sobre el mar, la difícil articulación de competencias en nuestro

\footnotetext{
${ }^{58}$ Ibidem, pp. 52-54.

${ }^{59}$ Cfr. art. 76 CONVEMAR.

${ }^{60}$ Sobre la participación de las CCAA, cfr. Disposición adicional 4ª del Real Decreto 1028/2007.
} 
Estado autonómico complica pero a la vez aconseja una planificación y acción integrada en el mar. Si en materia de ordenación del territorio como disciplina afín a la ordenación del medio marino, todas las CCAA han asumido la competencia exclusiva, algo parecido ha ocurrido con la ordenación del litoral, asunción que parece haber desatendido el legislador estatal a la hora de dictar el Real Decreto 1028/2007.

\section{Nuestra propuesta}

Los diversos usos del mar, que provocan entre sí conflictos vienen, en el mejor de los casos, amparados en políticas sectoriales que difícilmente consiguen una real coordinación. Quizás la solución debe venir de la mano del esperado Plan Estratégico Ambiental del Medio Marino Español que debería adoptar forma normativa y, a partir del mismo, articularse una planificación sectorial ordenada y subordinada, con una clara jerarquía, en cuya formulación intervinieran todas las Administraciones Públicas implicadas, siempre con la participación de los sectores afectados y del público en general. Y pudiera servir de inspiración el modelo alemán, cuyo Plan de desarrollo marítimo fue aprobado el 16 de septiembre de 2009 y cuya Ley de ordenación territorial (Raumordnungsgesetz) afecta a la zona marítima de aprovechamiento marítimo $^{61}$.

Dicho plan, claro está, debe vencer obstáculos de gran calado como la existencia de planes previos, piénsese en el referido EEALE, de zonificaciones ya operadas en el ámbito de las áreas marinas protegidas y de derechos adquiridos por los usuarios del mar en el ámbito de sectores como la navegación, la pesca, el recreo, el buceo y la acuicultura, entre otros. Por otra parte, este plan debe respetar la distinta articulación de competencias existente en las distintas zonas marítimas, así como en relación a las diversas actividades que se desarrollan en el mar y debe contemplar el especial carácter de los bienes afectados como el dominio público portuario y el dominio público marítimoterrestre, de los recursos naturales implicados y, en el caso que nos ocupa, del recurso eólico en el $\operatorname{mar}^{62}$.

\footnotetext{
${ }^{61}$ CALLEJÓN THÖMMES, D., "El fomento y la autorización de los parques eólicos en el derecho alemán”, en Torres López, Arana García, Energía eólica ... cit., pp. 457-468

${ }^{62}$ DELGADO PIQUERAS, "Naturaleza jurídica de la energía eólica” cit., pp. 205-248.
} 
Una reflexión importante en este sentido consiste en postular la concreción, el carácter programático de los planes sectoriales de desarrollo del Plan estratégico global de ordenación de los mares, lo que, en el ámbito que nos ocupa, evitaría la necesidad de abrir un procedimiento de concurrencia para estudiar y elegir el mejor proyecto, desde todas las ópticas. Así, la Administración predeterminaría, a la vista de toda la información disponible, la ubicación de los parques eólicos, evitándose de este modo el oportunismo de los competidores y la lamentable especulación que no tiene razón de ser en relación a unas instalaciones que ocupan una ubicación que constituye dominio público o res comunes omnium y que utilizan un recurso, el viento, que también queda fuera del comercio. Por lo anterior, consideramos que el procedimiento de concurrencia tiene su razón de ser en el ámbito de la contratación pública, así como en relación al fomento de políticas o a la convocatoria de beneficios ${ }^{63}$, o en relación al reparto de bienes escasos, pero no, como prevé el Real Decreto 1028/2007 objeto de estudio, para propiciar la competencia sobre un proyecto cuya iniciativa está perfectamente determinada y proviene del sector privado. Ello, a mi modo de ver, no hace sino desincentivar el emprendimiento en este campo.

Para la consecución de estos objetivos integradores esgrimidos, resultan interesantes los objetivos derivados de la aplicación de la Directiva 2007/2/CE, por la que se establece una infraestructura de información espacial en la Comunidad Europea (INSPIRE), que persigue fijar normas generales con vistas al establecimiento de una infraestructura de información espacial en la Unión, orientada a la aplicación de las políticas comunitarias de medio ambiente y de políticas o actuaciones que puedan incidir en el medio ambiente $^{64}$. Como es sobradamente conocido, la información, y en especial la información espacial, resulta necesaria para la correcta realización de la política ambiental comunitaria y de otras políticas o actuaciones que puedan incidir en el medio ambiente y por ende en el mar. En este sentido, la Directiva Inspire tiende a la adopción de medidas que atiendan al intercambio, puesta en común, acceso y utilización de datos espaciales interoperables y de servicios de datos espaciales, con la finalidad de

\footnotetext{
${ }^{63}$ Por ejemplo, la Resolución de 24 de noviembre de 2010, de la Secretaría de Estado de la Energía, que aprueba la convocatoria de un procedimiento de concurrencia competitiva para la obtención del derecho a la percepción de un régimen económico adicional a la retribución del mercado de producción de energía eléctrica para proyectos de instalaciones de producción de energía eléctrica de tecnología solar termoeléctrica de carácter innovador.

${ }^{64}$ A nivel interno, cfr. Ley 14/2010, de 5 de julio, sobre las infraestructuras y los servicios de información geográfica en España.
} 
establecer una infraestructura de información espacial en la Comunidad Europea (Inspire $)^{65}$. Inspire debe basarse en las infraestructuras de información espacial creadas por los Estados miembros, que sean utilizables y compatibles en un contexto comunitario y transfronterizo. La norma se aplica a los conjuntos de datos espaciales que se refieran a una zona sobre la que un estado miembro tenga o ejerza jurisdicción, que estén en formato electrónico, que obren en poder de una autoridad pública o de un tercero al que se le hubiera facilitado el acceso a la red (art. 4) y que trate uno de los temas recogidos en los Anexos I, II o III de la Directiva, que incluye sistemas de coordenadas de referencia, unidades administrativas, zonas marinas y demás masas de agua relacionadas con ellas, lugares protegidos dentro de un marco internacional, comunitario o interno, rutas marítimas, regiones marinas, rasgos geográficos oceanográficos, hábitat y biotopos y recursos energéticos -incluida la energía eólicaentre otros.

A nivel interno, la Ley 14/2010, de 5 de julio, sobre las infraestructuras y sistemas de información geográfica en España, que transpone la Directiva Inspire, tiene por objeto complementar la organización de los servicios de información geográfica y fijar, de conformidad con las competencias estatales, las normas generales para el establecimiento de infraestructuras de información geográfica orientadas a facilitar la aplicación de políticas basadas en la información geográfica por las Administraciones Públicas y el acceso y utilización de este tipo de información, especialmente las políticas de medio ambiente y políticas o actuaciones que puedan incidir en él (art. 1.1) . En consecuencia resulta aplicable a las políticas que contemplen la planificación eólica en el mar, en la medida en que afecta a información geográfica disponible sobre el territorio nacional, el mar territorial, la zona contigua, la plataforma continental y la zona económica exclusiva, generada o bajo responsabilidad de las Administraciones públicas.

Para finalizar, debemos destacar que precisamente esta falta de planificación integrada, junto con el gran número de órganos y Administraciones Públicas eventualmente implicadas, así como los dilatados plazos derivados del Real Decreto 1028/2007

\footnotetext{
${ }^{65}$ Existe un cierto grado de solapamiento entre la información espacial cubierta por la Directiva Inspire y la información a que se refiere la Directiva 2003/4/CE del Parlamento Europeo y del Consejo, de 28 de enero de 2003, relativa al acceso del público a la información medioambiental. La Directiva INSPIRE debe considerarse sin perjuicio de lo dispuesto en la Directiva 2003/4/CE y en la Directiva 2003/98/CE del Parlamento Europeo y del Consejo, de 17 de noviembre de 2003, relativa a la reutilización de la información del sector público, cuyos objetivos son complementarios a los de la presente Directiva.
} 
provocan incertidumbres que han desincentivado a los inversores e impedido el despliegue de la energía eólica marina en España. En esta línea, ya la Comunicación de la Comisión sobre Apoyo a la electricidad procedente de fuentes renovables de 2005 recomendó a los Estados miembros que ante la ineficacia del historial de los procedimientos autorizatorios de parques eólicos marinos, se establecieran directrices claras para estos procedimientos así como la reducción de los plazos ${ }^{66}$. A día de hoy, el reciente Plan de energías renovables 2011-2020 prevé, dentro del tercer gran grupo de iniciativas contempladas el de propuestas normativas y, entre éstas, la regulación de un procedimiento administrativo simplificado para plataformas experimentales $\mathrm{I}+\mathrm{D}$ de eólica y demás energías marinas.

El desarrollo de una economía competitiva, sostenible y ecológica puede ser una buena medida para la protección del empleo y la creación de puestos de trabajo. Ahora bien, como reza el Reglamento (UE) 1233/2010 del Parlamento Europeo y del Consejo, de 15 de diciembre de 2010, por el que se modifica el Reglamento (CE) n ${ }^{\circ} 663 / 2009$, por el que se establece un programa de ayuda a la recuperación económica mediante la concesión de asistencia financiera comunitaria a proyectos del ámbito de la energía, con miras a asegurar que el desarrollo de este sector tenga el impacto económico necesario a corto plazo, el período entre la recepción de una solicitud para el desarrollo de un determinado proyecto y la decisión final no debe ser superior a seis meses. El resultado de la conjunción de esta necesaria tendencia liberalizadora con la Evaluación de impacto ambiental será la asignatura pendiente.

\section{BIBLIOGRAFÍA}

ALENZA GARCÍA, J.F., "La autorización de parques eólicos marinos”, Sanz Larruga, F.J., García Pérez, M., Estudios sobre la ordenación, planificación y gestión del litoral: hacia un modelo integrado y sostenible, Fundación Pedro Barrié de la Maza e Instituto de Estudios Económicos de Galicia-Observatorio del litoral, A Coruña, 2009

BELTRÁN, M., "Parques eólicos Marinos en la Costa de Tarragona", Europa Azul, núm. 90, 2005.

\footnotetext{
${ }^{66} \mathrm{COM}(2005) 627$ final, de 7 de diciembre de 2005.
} 
BLESA MARTÍNEZ, B., "Nuevas tecnologías que contribuyen a mitigar el cambio climático: las instalaciones sostenibles en el mar territorial", Revista Aranzadi de Derecho Ambiental, núm. 18, 2011, pp. 341-354.

BUITRAGO MONTORO, A., GARAY IBARRECHE, B., "Energía eólica marina”, en Becher y otros (dirs.) Tratado de Energías Renovables II. Aspectos jurídicos, IberdrolaAranzadi, 2010.

CALLEJÓN THÖMMES, D., "El fomento y la autorización de los parques eólicos en el derecho alemán, Torres López, M. A., Arana García, E., (dirs.), Energía eólica: cuestiones jurídicas, económicas y ambientales, Civitas, Madrid, 2010

DELGADO PIQUERAS, F., "Naturaleza jurídica de la energía eólica", en Torres López, M. A., Arana García, E., (Dir.), Energía eólica: cuestiones jurídicas, económicas y ambientales, Civitas, Madrid, 2010

FERNÁNDEZ SALMERÓN, M., SORO MATEO, B., La articulación de competencias ambientales en el Estado autonómico, Atelier, 2001.

GARCÉS SANAGUSTÍN, A., "Régimen jurídico de la utilización de la energía eólica en Aragón”, RArAP, núm. 15, 1999.

GONZÁLEZ RÍOS, I, Régimen jurídico administrativo de las energías renovables y de la eficiencia energética, Thomson Reuters-Aranzadi, 2011

Informe renovables 2050: Un informe sobre el potencial de las energías renovables en la España peninsular, Instituto de investigación tecnológica, Comillas, 2005

LÓPEZ SAKO, M. J. "Situación actual y marco normativo de la energía eólica", en Torres López, M.A., Arana García, E., Moral Soriano, L. (coords), El sector eléctrico en España: competencia y servicio público, Comares Granada, 2007.

— Regulación y autorización de los parques eólicos, Civitas, Madrid, 2008

— "La autorización de los parques eólicos. Evolución de los procedimeintos e la normativa autonómica", en Torres López, M. A., Arana García, E., (dirs.), Energía eólica: cuestiones jurídicas, económicas y ambientales, Civitas, Madrid, 2010.

MARTÍNEZ PALACIO, A., RODRÍGUEZ RUIZ, J., "Energía eólica marina: una solución a considerar para un abastecimiento energético sostenible”, Ambienta: La Revista del Ministerio de Medio Ambiente, núm. 75, 2008. 
PAREJO NAVAJAS, T., La proyección de la ordenación física de los usos sobre la costa y el Mar próximo: la planificación del aquitorio, Iustel, 2011

QUINTANA LÓPEZ, T., "Régimen jurídico de la energía eólica”, REALA, núm. 291, 2003

SANZ LARRUGA, J., "Los parques eólicos marinos en el marco de la ordenación integral del litoral", http://www.observatoriodellitoral.es/subido/_documentos/congresos_y_foros/parques_e olicos marinos $y$ ordenacion integrada del litoral.pdf?PHPSESSID=b2662a1e31a40 6a00c93939cadaeed45

— "Los parques eólicos marinos en el marco de la gestión integrada del litoral", en Torres López, M. A., Arana García, E., (dirs.), Energía eólica: cuestiones jurídicas, económicas y ambientales, Civitas, Madrid, 2010.

SANZ LARRUGA, F.J., GARCÍA PÉREZ, M., Estudios sobre la ordenación, planificación y gestión del litoral: hacia un modelo integrado y sostenible, Fundación Pedro Barrié de la Maza e Instituto de Estudios Económicos de Galicia-Observatorio del litoral, A Coruña, 2009.

VÁZQUEZ GARCÍA, D., "Un nuevo impulso a las energías renovables en España: los parques eólicos marinos u Offshore”, La Ley, núm. 7.297, 2010. 